\title{
MRG proteins are shared by multiple protein complexes with distinct functions
}

\author{
Maëva Devoucoux ${ }^{1}$, Céline Roques ${ }^{1}$, Charles Joly-Beauparlant ${ }^{2}$, Arnaud Droit ${ }^{2}$, Samer M.I. \\ Hussein ${ }^{1}$ and Jacques Côté ${ }^{*}$
}

1. St. Patrick Research Group in Basic Oncology, Laval University Cancer Research Center,

Oncology division of CHU de Québec-Université Laval Research Center, Quebec City, QC G1R

3S3, Canada.

2. Axe Neurosciences, Centre de Recherche du CHU de Québec-Université Laval, Pavillon CHUL, 2705 boulevard Laurier, Quebec City, QC G1V 4G2, Canada ; Faculty of Medicine, Université Laval, 1050 ave de la Médecine, Quebec City, QC, Canada.

*Corresponding author: jacques.cote@crhdq.ulaval.ca

Running title: Various functions of MRG proteins interactome 


\title{
Highlights
}

- MRG15 and MRGX are stably associated with several different protein complexes important for genome expression and stability.

- Several MRG-containing complexes are chromatin modifiers

- Specific point mutations in the MRG domain differentially affect associated complexes.

- A major human complex homologous to the yeast TINTIN complex is identified.

- The protein EP400NL competes with EP400 to functionally separate TINTIN from the NuA4/TIP60 complex .

- TINTIN contains a bromodomain and a chromodomain to regulate transcription

\author{
Abbreviation \\ AP-MS, affinity purification combined to mass spectrometry; ASH1L, Absent, Small, or Homeotic \\ discs 1-Like; BRD, bromodomain; CHD, chromodomain; CTD, C-terminal domain; EP400NL, \\ EP400-N-terminal like; FPLC, Fast Protein Liquid Chromatography; K562, human \\ erythroleukemic cells; KAT, lysine acetyltransferase; KDAC, lysine deacetylase; MRG15, MORF- \\ related gene on chromosome 15; NuA4, Nucleosome Acetyltransferase of H4; RNAPII, RNA \\ polymerase II; SETD2, SET Domain containing 2; TINTIN, Trimer Independent of NuA4 involved \\ in Transcription Interactions with Nucleosomes; TIP60, Tat Interactive Protein 60kDa; U2OS, \\ human osteosarcoma epithelial cells.
}


Devoucoux et al. Page 3

\section{ABSTRACT}

MRG15/MORF4L1 is a highly conserved protein in eukaryotes that contains a chromodomain recognizing H3K36me3 in chromatin. Intriguingly, it has been reported in the literature to interact with several different factors involved in chromatin modifications, gene regulation, alternative mRNA splicing and DNA repair by homologous recombination. In order to get a complete and reliable picture of associations in physiological conditions, we used genome editing and tandem affinity purification to analyze the stable native interactome of human MRG15, its paralog MRGX/MORF4L2 that lacks the chromodomain, and MRGBP (MRG-binding protein) in isogenic K562 cells. We found stable interchangeable association of MRG15 and MRGX with the NuA4/TIP60 histone acetyltransferase/chromatin remodeler, Sin3B histone deacetylase/demethylase, ASH1L histone methyltransferase and PALB2/BRCA2 DNA repair protein complexes. These associations were further confirmed and analyzed by CRISPR-tagging of endogenous proteins and comparison of expressed isoforms. Importantly, based on structural information, point mutations could be introduced that can specifically disrupt MRG15 association with some complexes but not others. Most interestingly, we also identified a new abundant native complex formed by MRG15/X-MRGBP-BRD8-EP400NL that is functionally similar to the yeast TINTIN (Trimer Independent of NuA4 for Transcription Interactions with Nucleosomes) complex. Our results show that EP400NL, being homologous to the N-terminal region of NuA4/TIP60 subunit EP400, creates TINTIN by competing for BRD8 association. Functional genomics indicate that human TINTIN plays a role in transcription of specific genes. This is most likely linked to the H4ac-binding bromodomain of BRD8 along the H3K36me3binding chromodomain of MRG15 on the coding region of transcribed genes. Taken together, 
bioRxiv preprint doi: https://doi.org/10.1101/2021.08.11.456009; this version posted August 12, 2021. The copyright holder for this preprint (which was not certified by peer review) is the author/funder, who has granted bioRxiv a license to display the preprint in perpetuity. It is made available under aCC-BY-NC-ND 4.0 International license.

Devoucoux et al. Page 4

our data provide a complete detailed picture of human MRG proteins-associated protein complexes which is essential to understand and correlate their diverse biological functions in chromatin-based nuclear processes. 
Devoucoux et al. Page 5

\section{INTRODUCTION}

The eukaryote genome is organized into a structure called chromatin, with the nucleosomes being its basic units, playing central roles in the regulation of all DNA-based processes for genome expression and maintenance (1). One major element governing chromatin structure and functions is the diverse post-translational modifications (PTMs) deposited on the external tails of the nucleosomal histones (2). PTMs on specific residues of specific histones include acetylation, methylation, phosphorylation and ubiquitination, which are recognized by dedicated reader domains in factors to regulate biological processes $(3,4)$. Disruption of the enzymes that "write" or "erase" these histone marks, or their "readers", occurs in several human diseases, including cancer, leading to intense research efforts during the past several years to understand these regulatory interactions during cellular life (5).

One mark that has been studied extensively is the methylation of lysine 36 on histone H3 (H3K36me), which can occur as mono- (me1), di- (me2), or tri-(me3) methylation, levels being linked to distinct functions. While all methylation levels are generated by Set2 in Saccharomyces cerevisiae (6), mammalian methyltransferases like ASH1L and NSD1/2/3 only do H3K36me1/me2. Mammalian SETD2 on the other hand is responsible for H3K36me3 (7). Set2 associates with the elongating RNA polymerase II (RNAPII) phosphorylated on Ser2 of its Cterminal repeats (CTD). This leads to enrichment of H3K36me3 on the coding region of transcribed genes which recruits the RPD3S histone deacetylase complex to stabilize chromatin in the wake of RNAPII in order to avoid cryptic initiation and spurious transcription $(8,9)$. Mammalian SETD2 does not seem to affect global chromatin acetylation levels (7), even if H3K36me3 plays a central role in transcriptional activation and is distributed throughout the 
coding regions of active genes $(10,11)$. More precisely, H3K36me3 has been observed to be specifically enriched on exons, compared to introns, independent of nucleosome occupancy, in both yeast and mammals (12-14). These data were used to define a function of this histone mark in alternative mRNA splicing (15). It has been proposed that H3K36me3 is used as a platform recognized by the factor MORF-related gene on chromosome 15 (MRG15, a.k.a. MORF4L1) through its $\mathrm{N}$-terminal chromodomain (CHD), an interaction that recruits the splicing machinery $(16,17)$. The yeast homolog of MRG15, Eaf3, is also known to affect splicing through its binding with the splicing factor Prp45/SKIP, thereby leading to the recruitment of spliceosome on intron-containing genes (18).

Mammalian MRG15 has a paralog expressed for the X-chromosome, MRGX (a.k.a. MORF4L2), which lacks the chromodomain. MRG15/X seem to regulate cell proliferation and senescence is specific contexts, while only MRG15 is required for mouse development $(19,20)$. They have been found associated with both lysine acetyltransferase (KAT) and deacetylase (KDAC) complexes, namely NuA4/TIP60 and Sin3B, also conserved in yeast (NuA4 and RPD3S) and containing the homologous protein Eaf3 (21-25). While MRGX does not possess a Nterminal CHD, it shares with MRG15 a highly conserved C-terminal MRG domain, crucial for their non-histone protein-protein interactions (20). Interestingly, it has been suggested that MRG15 can form an homodimer which is dissociated by its acetylation, regulating MRG15 association with other factors (26). MRG15 is also involved in DNA repair through its interaction with DNA repair factor PALB2, thereby favoring repair of double strand breaks by homologous recombination (27-29). It has been recently described that the MRG15-PALB2 complex is associated with undamaged chromatin on active genes to protect them from 
genotoxic/replicative stress (30). Finally, MRG15 was very recently implicated in diurnal rhythm of epigenomic remodeling through chromatin acetylation as well as lipid metabolism through gene activation with LRH-1 (31)

Although current knowledge on MRG15 points towards quite distinct important roles in the cell and during development, its described functions and associated cofactors are often studied in very artificial non-physiological conditions. Here, we aimed at defining the complete detailed interactomes of $M R G 15 / X$ in the most native conditions possible. Tandem-affinity purification from isogenic cell lines identified several stable complexes containing MRG15 or MRGX. Endogenous protein tagging by CRISPR allowed validation and characterization of a new tetrameric protein complex with striking resemblance to the yeast TINTIN ( of NuA4 for Iranscription Interactions with ucleosomes) complex that we have previously identified (25). The presence of a bromodomain and a chromodomain in this complex and its effect on transcription supports the claim that we have identified a human TINTIN complex that associates with the body of active genes.

\section{EXPERIMENTAL PROCEDURES}

Recombinant Proteins and Pull-down Assay

Recombinant 6xHis-BRD8, GST-MRG15 CHD long and short, GST-EP400(aa194-446), GSTEP400NL(aa51-297) and GST-ASH1L(aa2040-2634) were expressed in E. coli BL21 cells grown in 


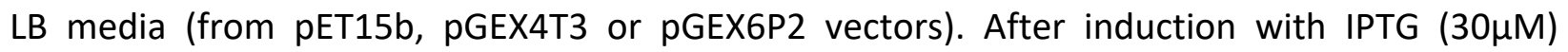
overnight at $16 \mathrm{C}$, bacteria were harvested and GST or 6xHistagged proteins were purified as previously described with minor modifications (32).

Protein and chromatin pull-down experiments were performed as previously described (33). The GST pulldown assays were performed using 300 to $600 \mathrm{ng}$ of GST-fused protein and an equivalent amount of His-tagged protein or $5 \mu$ g of native chromatin from HeLa cells, which was precleared using glutathione-Sepharose beads. Equivalent protein levels were estimated through Coomassie blue-stained SDS-PAGE by comparison with known amounts of bovine serum albumin (BSA) standards. After pre-clearing, the His-tagged proteins were incubated with GST-immobilized protein in binding buffer (25 mM HEPES pH 7.9, 10\% glycerol, $100 \mu \mathrm{g} / \mathrm{ml} \mathrm{BSA}$, $1 \mathrm{mM}$ PMSF, $0.5 \mathrm{mM}$ dithiothreitol (DTT), $0.1 \%$ Tween 20, and protease inhibitors, $250 \mathrm{mM} \mathrm{NaCl}$ was used for chromatin pull-down) at $4^{\circ} \mathrm{C}$ for $1 \mathrm{~h}$ to $4 \mathrm{~h}$ followed by washing the beads three times. To visualize the proteins, the beads were loaded on SDS-PAGE gels, followed by Western blotting with anti-GST (Sigma G1160), anti-His (Clontech 631212), anti-H3K36me2 (Upstate 07369), anti-H3K36me3(Abcam ab9050), anti-H3K79me3 (Abcam ab2621), and anti-H4 (Abcam ab7311). A GST-only protein and beads were used as a control.

\section{Experimental Model and Subject Details}

$\mathrm{K} 562$ and U2OS cells were obtained from the ATCC and maintained at $37^{\circ} \mathrm{C}$ under $5 \% \mathrm{CO}$. $\mathrm{K} 562$ were cultured in RPMI medium supplemented with $10 \%$ newborn calf serum and GlutaMAX. U2OS cells were cultured in DMEM medium supplemented with $10 \%$ fetal bovine serum. 
Establishment of Isogenic Cell Lines using the AAVS1 Safe Harbor or CRISPR/Cas9-mediated Genome Editing

K562 cells stably expressing 3xFLAG-2xStrep-tagged MRG15 spliced variants (long CHD or short CHD), MRGBP, MRGX, BRD8 spliced variants (one or two BRDs), EPC1 or EP400NL spliced variants (isoforms Q6ZTU2-5 and Q6ZTU2-6) were established as described before (34). BRD8, ASH1L, MRGX, and EP400NL were also endogenously 3xFlag-2xStrep-tagged using CRISPR/Cas9 with ouabain selection as previously described (35). The following gRNAs were used to generate these cell lines:

\begin{tabular}{|l|l|l|l|}
\hline \multicolumn{1}{|c|}{ Gene } & \multicolumn{1}{|c|}{ Part } & \multicolumn{1}{c|}{ Sequence for } & Sequence rev \\
\hline BRD8 & N-terminal & CCTCAGGGTTGGAGACTTCG & CGAAGTCTCCAACCCTGAGG \\
\hline BRD8 Q9H0E9- & & & \\
\hline MRGX & C-terminal & AAAGGCTCAAGTAGTCTGGA & TCCAGACTACTTGAGCCTTT \\
\hline EP400NL & C-terminal & TGTGAGCGTCTACAGACAGC & GCTGTCTGTAGACGCTCACA \\
\hline ASH1L & C-terminal & CTCAAAGAATGAGAACCTCAA & TTGAGGTTCTCATTCTTTGAG \\
\hline
\end{tabular}

Affinity Purification of Complexes

Native complexes were purified essentially as previously described (34). Briefly, Nuclear extracts were prepared from 2.5.10^9 cells and pre-cleared with CL6B sepharose beads. FLAG immunoprecipitations with anti-Flag agarose affinity resin (Sigma M2) were performed followed by two elutions with 3xFLAG peptide in elution buffer (20 mM HEPES-KOH [pH 7.9], 
10\% glycerol, $150 \mathrm{mM} \mathrm{KCl}$, 0.1\% Tween 20, 1mMDTT, $1 \mathrm{mM} \mathrm{PMSF,} 2 \mathrm{mg} / \mathrm{mL}$ Leupeptin, 5 $\mathrm{mg} / \mathrm{mL}$ Aprotinin, $2 \mathrm{mg} / \mathrm{mL}$ Pepstatin, $10 \mathrm{mM}$ Na-Butyrate, $10 \mathrm{mM} \beta$-glycerophosphate) with $200 \mu \mathrm{g} / \mathrm{mL}$ 3xFLAG peptide (Sigma). Then, STREP immunoprecipitations with Strep-tactin sepharose beads (Cedarlane) were performed followed by two elutions with elution buffer supplemented with $4 \mathrm{mM}$ biotin. Typically, $20 \mu \mathrm{L}$ of the first elution Strep was loaded on $\mathrm{Nu}$ PAGE 4\%-12\% Bis-Tris gels (Invitrogen) and analyzed via silver staining. Fractions were then analyzed by mass spectrometry and western blotting. For purification after inducing DNA damage, cells were treated with $50 \mathrm{ng} / \mathrm{mL}$ of neocarzinostatin (NCS) for $3 \mathrm{~h}$ before beung collected to prepare the nuclear extract.

\section{Mass Spectrometry Analysis}

Mass spectrometry analyses were performed by the Proteomics Platform of the CHU de Québec-Université Laval Research Center (Québec, Qc, Canada). Samples were analyzed by nano-LC/MSMS either with a 5600 triple TOF or an Orbitrap Fusion.

5600 triple TOF: Peptides were analyzed using an Ekspert NanoLC425 coupled to a 5600+ triple TOF mass spectrometer (Sciex, Framingham, MA, USA). Peptides were trapped at $4 \mu \mathrm{l} / \mathrm{min}$ in loading solvent $(0.1 \%$ formic acid) on a $5 \mathrm{~mm}$ × $300 \mu \mathrm{m}$ C18 pepmap cartridge pre-column (Thermo Fisher Scientific / Dionex Softron GmbH, Germering, Germany) for 10 minutes. Then, the pre-column was switched online with a self-packed picofrit column (New Objective) packed with reprosil 3u, 120A C18, $15 \mathrm{~cm} \times 0.075 \mathrm{~mm}$ internal diameter, (Dr. Maisch). Peptides were eluted with a linear gradient from $5-35 \%$ solvent $B(A: 0.1 \%$ formic acid, $B$ : acetonitrile, $0.1 \%$ formic acid) in 35 minutes, at $300 \mathrm{~nL} / \mathrm{min}$ for a total run time of $60 \mathrm{~min}$. Mass spectra were 
acquired using a data-dependent acquisition mode using Analyst software version 1.7. Each full scan mass spectrum (400 to $1250 \mathrm{~m} / \mathrm{z}$ ) was followed by collision-induced dissociation of the twenty most intense ions. Dynamic exclusion was set for $12 \mathrm{sec}$ and tolerance of $100 \mathrm{ppm}$.

Orbitrap fusion: Peptides were analyzed using a Dionex UltiMate 3000 nanoRSLC chromatography system (Thermo Fisher Scientific) connected to an Orbitrap Fusion mass spectrometer (Thermo Fisher Scientific, San Jose, CA, USA). Peptides were trapped at $20 \mu \mathrm{l} / \mathrm{min}$ in loading solvent ( $2 \%$ acetonitrile, $0.05 \%$ TFA) on a $5 \mathrm{~mm} \times 300 \mu \mathrm{m}$ C18 pepmap cartridge precolumn (Thermo Fisher Scientific / Dionex Softron GmbH, Germering, Germany) for 5 minutes. Then, the pre-column was switched online with a Pepmap Acclaim column (ThermoFisher) 50 $\mathrm{cm} \times 75 \mu \mathrm{m}$ internal diameter separation column and the peptides were eluted with a linear gradient from $5-40 \%$ solvent B (A: 0,1\% formic acid, B: $80 \%$ acetonitrile, $0.1 \%$ formic acid) in 60 minutes, at $300 \mathrm{~nL} / \mathrm{min}$ for a total runtime of $90 \mathrm{~min}$. Mass spectra were acquired using a datadependent acquisition mode using Thermo XCalibur software version 4.3.73.11. Full scan mass spectra (350 to $1800 \mathrm{~m} / \mathrm{z}$ ) were acquired in the orbitrap using an AGC target of $4 \mathrm{e} 5$, a maximum injection time of $50 \mathrm{~ms}$, and a resolution of 120 000. Internal calibration using lock mass on the $\mathrm{m} / \mathrm{z} 445.12003$ siloxane ion was used. Each MS scan was followed by MSMS fragmentation of the most intense ions for a total cycle time of 3 seconds (top speed mode). The selected ions were isolated using the quadrupole analyzer in a window of $1.6 \mathrm{~m} / \mathrm{z}$ and fragmented by Higher energy Collision-induced Dissociation (HCD) with $35 \%$ of collision energy. The resulting fragments were detected by the linear ion trap at a rapid scan rate with an AGC target of 1e4 and a maximum injection time of $50 \mathrm{~ms}$. Dynamic exclusion of previously fragmented peptides was set for $20 \mathrm{sec}$ and a tolerance of $10 \mathrm{ppm}$. 
Database searching: MGF peak list files were created using Protein Pilot version 4.5 software (Sciex) for the data obtained with the 5600+ triple TOF and with Proteome Discoverer 2.3 software (Thermo) for the orbitrap data. The MGF sample files were then analyzed using Mascot (Matrix Science, London, UK; version 2.5.1). Mascot was set up to search a contaminant database and Uniprot Homo sapiens database assuming the digestion enzyme trypsin. Mascot was searched with a fragment ion mass tolerance of $0.60 \mathrm{Da}$ (orbitrap) or 0.1Da (5600+) and a parent ion tolerance of $10.0 \mathrm{ppm}$ (orbitrap) and 0.1Da (5600+). Carbamidomethyl of cysteine was specified in Mascot as a fixed modification. Deamidation of asparagine and glutamine and oxidation of methionine were specified in Mascot as variable modifications. 2 missed cleavages were allowed.

Criteria for protein identification: Scaffold (version Scaffold_4.8.7, Proteome Software Inc., Portland, OR) was used to validate MS/MS-based peptide and protein identifications. Peptide identifications were accepted if they could be established at greater than $8.0 \%$ probability to achieve an FDR less than $1.0 \%$ by the Scaffold Local FDR algorithm. Protein identifications were accepted if they could be established at greater than $99.0 \%$ probability to achieve an FDR less than $1.0 \%$ and contained at least 2 identified peptides. Protein probabilities were assigned by the Protein Prophet algorithm (36). Proteins that contained similar peptides and could not be differentiated based on MS/MS analysis alone were grouped to satisfy the principles of parsimony. Data were further analyzed using the CRAPome online tool (www.crapome.org).

All MS files generated as part of this study were deposited at MassIVE (http://massive.ucsd.edu). The MassIVE ID is MSV000087245 and the MassIVE link for download 
http://massive.ucsd.edu/ProteoSAFe/status.jsp?task=9534fb8b77634860938b1139a53d9df8.

The password for download prior to final acceptance is MRG15.

Antibodies and siRNAs

The following antibodies were used for Western blotting at the indicated dilution: anti-FLAG HRP conjugate (Sigma M2, 1:10000); anti-Brd8 (Bethyl A300-219A, 1:10000); anti-DMAP1 (Thermoscientific PA1-886, 1:1000); anti-P400 (Abcam ab5201, 1:1000); anti-MRG15 (Active Motif 39361, 1:1000); anti-MRGBP (Abnova H00055257-B01, 1:2000); anti-MRGX (Abnova PAB6152, 1:1000); anti-KAT5/Tip60 (Abcam ab137518, 1:1000); anti-ASH1L (Bethyl A301-749, 1:1000); anti-KDM5A (Cell signaling 3876, 1:1000); anti-Pf1 (Bethyl A301-647, 1:1000); antiPALB2 (Bethyl A301-246, 1:3000); anti-AKAP8 (Abcam ab72196, 1:2500); anti-GAPDH (Thermofisher 39-8600, 1:10000); anti-KAP1 (MAB3662, 1/4000).

The following siRNA were used against the indicated proteins: KAT5/TIP60 smartpool (Dharmacon, CCACAGAUCACCAUCAAUG, GAACAAGAGUUAUUCCAG,

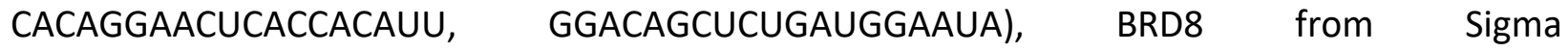
(SASI_Hs01_00131635; target sequences start at nucleotide 2223); MRG15 smartpool (Dharmacon, GAAGAGCCUUGCUUUAUUA, UAAAGUACCUGGCAAAGAA, GUACCCAGCUACUCUAUAA, GAUGACUgGgACUUAAUUA); MRGX smartpool (Dharmacon, gCACUCAGCUGCUCUACAA, GAgGAgGCGUUUAAGAUA, GCAGgGAAAUGUGAUAA, GCUCCAAUGUCCCAGGUUU), MRGBP smartpool (Dhaarmacon, GAAGAACUCCUCAGACUUG, GAACUUCGUCCUUCCAGAA, GAACCGACACUUCCACAUG, ACAAAGUCCUGACCGCAAA), and 
siLuciferase as control is used (DOYYA, AACUGACGCGGAAUACUUCGA). Knockdown efficiency was validated by RT-qPCR with the following primers:

\begin{tabular}{|l|l|r|}
\hline \multicolumn{1}{|c|}{ Targets } & \multicolumn{1}{|c|}{ primers for } & primers rev \\
\hline BRD8 & ATGGTGGGGAGATACAGCAA & AGTATGTGGATCCCCCACAG \\
\hline KAT5/TIP60 & CATCCTCCAGGCAATGAGAT & ACTTGGCCAAAAGACACAGG \\
\hline MRG15 & CACCCATGTCCCAGGTGTAT & GCAAGGCTCTTCTCATCCAG \\
\hline MRGX & GTGTGCTTGCTTGGAGATCA & TCAGGGAAGGTTCTGCAATC \\
\hline MRGBP & GGAGGAGACAGTGGTGTGG & CATGTGGAAGTGTCGGTTCA \\
\hline
\end{tabular}

In Vitro Histone Methyltransferase Assay

Purified endogenous ASH1L (or truncated recombinant GST-ASH1L(aa2040-2634)) was first preincubated with recombinant MRG15 purified from baculovirus (or the same amount of BSA) and $0.5 \mu \mathrm{g}$ of native Short OligoNucleosomes (SON) purified from HeLa cells for $4 \mathrm{~h}$ at $30 \mathrm{C}$ in a $20 \mu \mathrm{l}$ reaction containing $100 \mathrm{mM}$ Tris- $\mathrm{HCl}$ pH8.0, 25\% glycerol, 0.5mM EDTA, 5mM DTT, 5mM PMSF, $10 \mathrm{mM} \mathrm{MgCl}_{2}$ for $30 \mathrm{~min}$ at $4 \mathrm{C}$. Then, $2 \mu \mathrm{L}$ of ${ }^{3} \mathrm{H} \mathrm{S}$ - adenosyl methionine (0.55uCi/ul) was added and the mixture was incubated for $3 \mathrm{~h}$ at $30 \mathrm{C}$. the reaction was then spotted onto $\mathrm{p} 81$ filter paper, washed in carbonate buffer and scintillation counting was used to determine the incorporation.

RNA-sequencing Analysis

2 days post-Knockdown (KD) of MRG proteins, BRD8 or KAT5 in U2OS cells, RNA was extracted with the Monarch Total RNA Miniprep Kit (NEB \#T2010), following the manufacturer's 
indications. Then, at least $1.5 \mu \mathrm{g}$ of RNA were depleted of rRNAs using the NEB rRNA-depletion kit (HMR) followed by Illumina library preparation. Finally, cDNAs were sequenced using the NovaSeq6000 S2 for 50M of PE100 reads. Two replicates of each KD were sequenced. Raw sequences and processed data of short reads RNA-sequencing from U2OS cells were deposited in the GEO database under accession number GSE181533.

\section{Gene expression analysis}

Raw fast5 files were base called using Guppy v.4.2.2 with the guppy_basecaller command and the dna_r9.4.1_450bps_fast.cfg configuration file and default settings. Barcodes were detected and reads were separated with the guppy_barcoder using the default settings. The resulting FASTQ reads were aligned to the hg19 human reference with Minimap2 with the following parameters: -aLx splice --cs=long. Raw read counts were obtained with the featureCounts tool from the Subread package $v 2.0 .0$, using the exon counting mode $(37,38)$. EdgeR R-package (v3.12.1) was then used to normalize the data, calculated RNA abundance at the gene and transcript levels (as counts per million reads (CPM), and perform statistical analysis (39). Briefly, a common biological coefficient of variation (BCV) and dispersion (variance) were estimated based on a negative binomial distribution model. This estimated dispersion value was incorporated into the final EdgeR analysis for differential gene expression, and the generalized linear model (GLM) likelihood ratio test was used for statistics, as described in EdgeR user guide. Analysis of variations in gene expression was performed by comparing KDs BRD8, MRGBP, MRG15, MRGX, and KAT5/TIP60 to siControl (siLuciferase). From all genes showing differential expression, a cutoff of 2-fold difference was applied to the Log2(fold change) values between the selected sample and control. 
mRNA splice variants analysis

Reads were trimmed using fastp v0.20.0 (40). Quality check was performed on raw and trimmed data to ensure the quality of the reads using FastQC v0.11.8 and MultiQC v1.8 $(41,42)$. The quantification was performed with Kallisto v0.46.2 (43). Differential expression analysis was performed in R v4.0.0 using the DESeq2 v1.28.1 $(44,45)$. Analysis of variations in splice isoform expression was performed by comparing differential expression at the gene and transcript levels. From all genes showing no differential expression with the selected control (padj $\geq 0.1$ ), those with significant differences in transcript expression (padj $\leq 0.1$ ) were selected. To highlight the genes with high changes in transcript expression compared to gene expression, a cutoff of 2-fold difference was applied to the Log2(fold change) values between the selected sample and control.

\section{Reverse Transcription-qPCR}

siRNAs for KD of BRD8 or MRG15 or MRGBP or MRGX or KAT5/TIP60 were transfected in U2OS cells. siLuciferase (siLuc) was used as control. 48hrs later total RNA was extracted with the RNeasy Plus Mini kit (QIAGEN). 500 ng of RNA was reverse transcribed by oligo-dT and random priming into cDNA with a qScript cDNA SuperMix kit (QuantaBio-VWR), according to the manufacturer's instructions. Quantification of the amount of cDNA was done with SYBR Green I (Roche) on a LightCycler 480 (Roche) for real-time PCR. The RPLPO gene was used as a housekeeping internal control for normalization. The error bars represent the range based on independent experiments. The oligonucleotide sequences used for expression analysis by RTqPCR are listed below: 


\begin{tabular}{|l|l|l|}
\hline \multicolumn{1}{|c|}{ Targets } & \multicolumn{1}{|c|}{ primers for } & \multicolumn{1}{c|}{ primers rev } \\
\hline RFX8 & GTCATGCTGATGTCATTGCCT & CCAAGAAGTCATGAAGGAGAACA \\
\hline HHIP & GGGCGCCTGGAGAATAAGATA & GGCTTTGAGAATGTGGAGAGC \\
\hline SYTL5 & TATGCAGGGAGTGTCGAGTTG & GTGCCGAGAACATTGACTTGC \\
\hline CD180 & TGAAGGGTCTGAACTTGCTCA & TAGAGGTGTGTAAGGGAGGGG \\
\hline AKT2 & CCGCTACTACGCCATGAAGAT & AACGGGTGCCTGGTGTTC \\
\hline PRRG4 & GCATTTTGGCAGGAATATTCAGC & CCAGCAGCAATTAATCCAGTCAG \\
\hline PCDHB9 & AGGATCTGGGACTAGCAGAGG & CAGCTTCTCTCGGTCCAGTTT \\
\hline RPLP0 & CGACCTGGAAGTCCAACTAC & ATCTGCTGCATCTGCTTG \\
\hline
\end{tabular}

Experimental Design and Statistical Rationale

A mock K562 cell line expressing an empty 3xFlag-2xStrep tag from the AAVS1 locus is used as control. Each Knockdown in U2OS cells was performed in biological duplicates. Control with a siluciferase was generated concomitantly to experimental samples. RT-qPCRs to validate Knockdown and RNA-sequencing were performed in biological duplicates. Error bars represent the range from two biological replicates. Statistical analyses were performed via two-way ANOVA using Prism version 7 (GraphPad software inc California, USA) followed by Tukey's test. P-values $<0.05$ were considered significant. 


\section{RESULTS}

\section{Impact of the CHD on the binding to of MRG proteins to chromatin.}

Although MRG15 is highly conserved from yeast to human, it is interesting to observe that two isoforms are produced in mammals through alternative mRNA splicing and that a paralogous protein, MRGX, is produced by another gene. Interestingly, the major difference between these 3 proteins resides in the chromodomain (CHD). MRG15 isoforms contain either a "long CHD" (Q9UBU8-1 in Uniprot) with an extra 39 amino acids (aa) insert or a "short CHD" (Q9UBU8-2 in Uniprot) which is considered canonical. In contrast, MRGX lacks the CHD region at its $\mathrm{N}$ terminus (Fig. 1A). Yeast Eaf3 in comparison also has a "long CHD" but the extra insert is located on the opposite side of the hydrophobic cage that recognizes H3K36me3 compared to MRG15 (Fig. S1A). The proteins are characterized by a 175aa MRG domain at their C-terminus, important for their non-histone protein-protein interactions (20). Eaf3 CHD has been shown to bind H3K36me2/me3 which is required for suppression of spurious intragenic transcription by the RPD3S histone deacetylase complex $(24,46,47)$. While Eaf3 CHD has been argued to also bind H3K4me3 in vitro, MRG15 short CHD does not show any interaction with this mark (48). We then wondered if the insert in MRG15 long CHD isoform could change its binding properties. To test that, we performed GST pull-down experiments with purified native chromatin and recombinant proteins containing the short or long CHD of MRG15. The short CHD showed great specificity for $\mathrm{H} 3 \mathrm{~K} 36 \mathrm{me} 3$, compared to $\mathrm{H} 3 \mathrm{~K} 36 \mathrm{me} 2$, while the long $\mathrm{CHD}$ seem to have weaker affinity (Fig. 1B).

To further examine the potential impact of the CHD size and or its absence on chromatin binding in vivo, we generated isogenic K562 cell lines with a single copy of the epitope-tagged 
(3xFlag-2xStrep) MRG15 isoforms or MRGX cDNA inserted at the AAVS1 safe-harbor locus, as described before (Fig. S1B)(34). We then analyzed their genome-wide locations using ChIP-seq experiments with an anti-Flag antibody. MRG15-S, MRG15-L and MRGX seem the share the vast majority (>70\%) of their genomic targets, independently of the CHD status (Fig. S1C). On the other hand, MRG15-L had a relatively much smaller number of bound regions that could be mapped, possibly reflecting a looser interaction with chromatin. It remains to be seen if the small proportion of genomic regions uniquely bound by MRGX or MRG15 are functionally significant.

MRG proteins are associated with several distinct protein complexes but are interchangeable.

As mentioned above, several associated factors have been identified for mammalian canonical MRG15 (short CHD/MRG15-S), often using methods like transient or stable over-expression and simple immunoprecipitations. Thus, we wanted to get a full picture of the associated complexes in the most native conditions using our validated approaches. At the same time, we investigated if MRG15-L, MRG15-S and MRGX have different interactomes. Even though the AAVS1 system usually allows near physiological level of expression (within 2-2.5-fold (34)), it does not recapitulate native regulation by endogenous promoters and 5'/3'UTRs. We were able to tag the endogenous MRGX gene using an improved CRISPR/Cas9 genome editing method (35). We used a gRNA targeting the codon stop of MRGX to introduce the 3xFlag-2xStrep tag (Fig. S1D). Comparing endogenous versus AAVS1-mediated expression levels indicates 
significantly lower endogenous expression, but similar to MRG15 expression from AAVS1 (Fig. S1B).

We then performed tandem affinity purifications with native elution at both steps, as previously described $(34,49)$. The final elutions with biotin were then analyzed by silver staining, mass spectrometry and western blotting (Fig. 1C-E, Table S1). In agreement with the highly conserved MRG domain between MRG15 and MRGX, we observed very similar interactomes for all MRG proteins. We could detect the full set of subunits for the NuA4/TIP60 acetyltransferase complex as well as the Sin3B deacetylase complex (homologous to yeast RPD3S) that includes the KDM5A H3K4 demethylase. It is interesting to point out that MRG15 and MRGX proteins are mutually exclusive in their associations since we cannot MRGX in MRG15 preps and vice versa (Fig. 1D and Table S1). MRG15-S and MRGX have also been previously linked to PALB2/BRCA2, playing a crucial function in DNA repair by homologous recombination $(27,29,30)$ and we confirmed that (Fig. 1E, Table S1). This interaction seems stable and not modulated by a cellular DNA damage response since we obtained very similar results purifying MRG15-S from cells treated with DNA double-strand break-inducing agent neocarzinostatin (NCS), for PALB2/BRCA2 or any other interacting partners (Table S1, right panel), in agreement with the proposed role of MRG15/PALB2/BRCA2 in protecting undamaged chromatin on active genes (30). MRFAP1 is also an interesting interactor of both MRG15 spliced isoforms and MRGX as it was known to form a complex with MRG15-S through regulation of NEDDylation (50). Finally, a particularly interesting shared interaction is with the H3K36 methyltransferase ASH1L (Fig. 1E, Table S1). 


\section{Endogenous ASH1L is associated with MRG proteins.}

ASH1L is a member of the trithorax group proteins involved in activation of Hox genes in Drosophila. Its methyltransferase activity is crucial for H3K36me1/me2 maintenance, thereby leading to MLL recruitment on its specific promoter targets $(51,52)$. The catalytic activity of ASH1L seems also important for DNA repair via nucleotide excision (53). Moreover, previous studies have been shown that MRG15 and MRGX enhance the methyltransferase activity of a truncated version of $\operatorname{ASH} 1 \mathrm{~L}(54,55)$. Indeed, this binding can affect the auto-inhibitory loop of ASH1L $(56,57)$. Importantly, this stimulatory effect is therefore independent of the H3K36mebinding CHD of MRG15. To confirm this association and biochemical studies in the physiological context, we were able to tag and purify endogenous ASH1L using the CRISPR/Cas9 system in K562 cells (Fig. 2A, S1E). We then analyzed by western blots and mass spectrometry the ASH1L interactome. We confirmed association of MRG15 and MRGX as well as Nurf55, an already known factor link to ASH1L (Fig. 2B, Table S2). Interestingly, the A Kinase Anchoring protein 8 (AKAP8) and multiple RNA-processing factors were also found associated with ASH1L, assuming a potential function in alternative splicing, as it was already described for AKAP8 (58).

To confirm the role of MRG15 in stimulating ASH1L methyltransferase activity, we performed an in vitro histone methyltransferase assay (HMT) to measure its activity. We used a recombinant truncated version of ASH1L (aa 2040-2684), preincubated with recombinant MRG15 or BSA. As expected, MRG15 greatly enhanced the methyltransferase activity of ASH1L

(Fig. 2C). In parallel, the methyltransferase activity of the purified endogenous ASH1L was not affected by the preincubation with recombinant MRG15. This strongly suggests that the vast 
majority of endogenous ASH1L is stably bound to an MRG protein in vivo, being fully active and non-responsive to addition of exogenous MRG15.

\section{Genetic mutations to modulate MRG15 association with distinct complexes}

Previous work has been done to characterize the structure of the MRG domain as an interface for protein-protein interactions $(20,59)$. Based on this information, we investigated if we could manipulate the association of MRG proteins with distinct complexes in native conditions. We generated K562 cell lines expressing tagged MRG15 carrying the W172A and Y235A substitutions in its MRG domain (Fig. 3A). After purification and analysis by silver-stained gel, western blot and mass spectrometry, we can conclude that these mutations specifically disrupt MRG15 association with the Sin3B deacetylase complex, BRCA2/PALB2, MRFAP1 and ASH1L

(Fig. 3C-D, Table S3). Strikingly, MRG15 association with the NuA4/TIP60 complex is not affected, indicating that distinct molecular features of the MRG domain allow the multispecificity of protein interactions and therefore associations to complexes. These mutants could help address the functional implication of MRG proteins association with these partners versus its presence in NuA4/TIP60. To see if it would be possible to address the opposite question, we again used published structural information (20) and introduce point mutations in the MRGbinding protein MRGBP, a subunit of NuA4/TIP60 directly associated with MRG15/X in the complex. We generated K562 cell lines expressing tagged wild-type and mutant MRGBP carrying the W78A F105A substitutions (Fig. 3A). Analysis of the purified fractions showed that the double mutant disrupted the association of MRG15 and MRGX with the native NuA4/TIP60 
complex without affecting other components (Fig. 3D-E). Together, these MRG mutants have the potential to help us understand the specific function of MRG protein in distinct complexes. For example, as mentioned before, MRG15 is known to have a function in the repair of DNA double-strand breaks by homologous recombination, certainly in part through its association with PALB2/BRCA2 $(27,29,30,60)$. Furthermore, the NuA4/TIP60 complex plays also plays a role in DNA repair, promoting homologous recombination (61-63). Thus, taking advantage of its mutants, it will be possible to characterize the function of MRG15 in DNA repair, distinguishing its role from within the NuA4/TIP60 complex versus its association with PALB2/BRAC2.

\section{The MRG interactomes identify a new tetrameric protein complex}

When we analyzed the interactomes of MRG15-S/L and MRGX, we noticed by gel, western and mass spectrometry the over-representation of specific subunits of NuA4/TIP60. This was the case for MRGBP and the bromodomain-containing protein BRD8. That drew a parallel with a similar observation we made with yeast NuA4 components a few years ago (25). At that time, we noticed that MRG15 and MRGBP homologs, Eaf3 and Eaf7, were preferentially enriched when used as bait, along the protein Eaf5 which has no clear homolog in higher eukaryotes. We went on to characterize a yeast trimeric complex of Eaf5-Eaf7-Eaf3 that exists independently of NuA4, binds the coding region of active genes and interacts with the

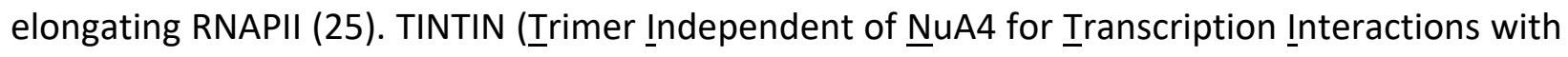
Nucleosomes) is involved in transcription elongation presumably by facilitating disruption and 
recycling of nucleosomes from the front to the back of the elongating polymerase, also helping to suppress spurious transcription (64).

Since our purification of MRGBP, the human homolog of Eaf7, also yielded over overrepresentation of MRG15/X and BRD8 compared to the rest of NuA4/TIP60 subunits (Fig. 3D, 4A), we wondered if MRG15 in higher eukaryotes could also form an independent functional complex like yeast TINTIN, in which BRD8 would be the functional homolog of yeast Eaf5. To test this hypothesis, we generated K562 cell lines using the AAVS1 system to purify BRD8 in comparison to MRGBP (Fig. S2A). Interestingly, BRD8 possesses two isoforms produced by alternative mRNA splicing, a shorter version with one H4ac-binding bromodomain (BRD) (Q9H0E9-2 to -4) and a longer version with two BRDs (Q9H0E9-1). Using the CRISPR/Cas9 system, we were able to tag both endogenous isoforms. We designed gRNAs to target the Cterminal of the two-BRD isoform or the $\mathrm{N}$-terminal of the BRD8 gene, tagging both isoforms (Fig. S3B). Although clonal selection shows the introduction of our tag in the C-terminus of the long isoform, we were not able to detect expression of this specific variant compared to the $\mathrm{N}$ terminal tagging (Fig. S3C). Strangely, even expressing the 2BRD isoform from the AAVS1 locus yielded very low signal, arguing that this isoform is unstable in K562 cells.

We tandem affinity purified MRGBP-3xFlag-2xStrep and BRD8-3xFlag-2xStrep expressed from AAVS1 or endogenously tagged and analyzed the fractions by silver staining, mass spectrometry and western blots with the annotated antibodies (Fig. 4A-B, Table S4). Surprisingly, in those purifications, but also in our previous MRG15/X purifications, we detected an uncharacterized factor, called EP400 N-terminal like or EP400NL (Fig. 1D and 4B, Tables S1, S3 and S4). EP400NL was first described as a pseudogene and is homologous to a short region 
at the $5^{\prime}$ of the EP400 gene (Fig. S2D). It can produce multiple spliced variants but only two of them (Q6ZTU2-5 and Q6ZTU2-6) with a specific C-terminal sequence were found associated with MRG proteins and BRD8 by mass spectrometry results (Table S1, S3 and S4). Thus, EP400NL proteins share a similar N-terminal sequence with the very large EP400 protein, an essential ATP-dependent remodeler and scaffolding subunit of the NuA4/TIP60 complex (Fig. S3D $)(34,65)$.

\section{EP400NL creates a human TINTIN complex by competing with EP400 for association to}

\section{trimeric BRD8-MRGBP-MRG15/X}

To prove the existence of this functional module independent of the NuA4/TIP60 complex, we purified BRD8 and MRGBP as above, but in parallel to the NuA4/TIP60-specific subunit EPC1 (61). We then loaded the tandem affinity-purified fractions on a Superose 6 size exclusion column to visualise distinct assemblies. Fractions from the gel filtration were analyzed by Western blot, silver-stained gel and mass spectrometry (Fig. 4C-D, Table S5). While the purified EPC1 fraction eluted early as expected with the large size of the NuA4/TIP60 ( 2MDa), BRD8 eluted as two populations with the strongest signal associated with a smaller protein complex ( 700-800 KDa) (Fig. 4C-D). This smaller population also co-eluted with the strongest signal of MRGBP and MRG15/X proteins. Importantly, in contrast to these proteins, EP400NL was only detected in the smaller size fraction, with no signal eluting with NuA4/TIP60. These results demonstrate the existence of a human TINTIN complex formed by EP400NL-BRD8-MRGBPMRG15/X. Gel filtration of the purified MRGBP fraction gave similar results but with an important difference. In this case, a third much smaller population was detected below $150 \mathrm{kDa}$ 
and containing likely only MRGBP and MRG15/X (Fig. 4C-D, Table S5). Altogether, these data support the idea that the human TINTIN exists independently of the NuA4/TIP60 complex with potential functions in transcription as it was observed in yeast.

Since EP400NL was previously described as a pseudogene, we generated K562 cell lines using both AAVS1 and CRISPR/Cas9 to, on one hand, tag the specific isoform Q6ZTU2-5 and, on the other hand, the endogenous gene at the C-terminus to tag the two specific isoforms found by mass spectrometry (Fig. S2E-F). We then used those cell lines to demonstrate physiological expression of the endogenous EP4OONL gene and characterize the encoded protein interactome. Analysis of the tandem affinity-purified fractions confirmed expression of EP400NL by the endogenous gene and showed strong, apparently stoichiometric, association with BRD8, MRGBP and MRG15/X (Fig. 5A-B, Table S6)(note that MRGBP does not stain efficiently with silver, while showing strong signal by mass spectrometry). Importantly, did not purifiy with any other known components of NuA4/TIP60. Interestingly, an unusually high number of peptides from mRNA processing factors were found, suggesting a potential function of human TINTIN in mRNA processing or at least a close proximity during transcription elongation (Table S6).

If EP400NL competes with EP400 to keep human TINTIN separated from the NuA4/TIP60 complex, it is important to identify its binding target. Direct physical interactions between BRD8 and MRGBP as well as MRGBP and MRG15 have been reported $(20,66)$. We have shown that Eaf5 is responsible for anchoring TINTIN to the yeast NuA4 complex, where it binds the first 85 aa of Eaf1, the scaffolding subunit homologous to EP400 $(25,67,68)$. Thus, if BRD8 is 
really the human functional homolog of yeast Eaf5, it should be responsible to bridge MRGBPMRG15/X to EP400 in NuA4/TIP60 or EP400NL in TINTIN. To answer this question, we performed a pull-down assay with full-length recombinant BRD8 and GST fusions with homologous N-terminal regions of EP400 (aa194-446) and EP400NL (aa51-297) (see Fig. S2D). BRD8 was very efficiently pulled down by both fusions but not GST control, thereby confirming our hypothesis (Fig. 5C). Thus, BRD8 acts like the bridge that anchors the MRG proteins to the NuA4/TIP60 complex and EP400NL can block this interaction by associating with BRD8 through its homology to EP400, freeing the TINTIN complex in the cell (Fig. 5D).

\section{The human TINTIN complex regulates both transcription and transcript isoforms of specific} genes

The yeast TINTIN was shown to interact with the elongating RNAPII and to be involved in recycling disrupted nucleosomes in its wake to suppress spurious transcription (25). To test if human TINTIN also has a role in transcription, we performed siRNA-mediated knockdowns (KDs) of TINTIN components in comparison to KAT5/Tip60 knockdown, in an attempt to distinguish functions associated with NuA4/TIP60 vs independent TINTIN (Fig. S3A-B). RNAs were extracted $48 \mathrm{~h}$ post-KDs and mRNA-sequencing was performed from samples depleted either for BRD8, MRGBP, MRG15 or KAT5/Tip60. 431 common genes were found downregulated in all KDs compared to siControl while and 529 common genes were upregulated (Fig. 6A). These likely reflect the function of the NuA4/TIP60 complex. Due to the mutual exclusion of MRG15 and MRGX, we also compared KD of MRGX with the other KDs and 
found over 500 common genes downregulated or upregulated (Fig. S3C). Thus, some specific genes seem differently affected by the MRGX-containing NuA4/TIP60 complex versus the MRG15-containing one. Furthermore, when we excluded specific targets affected by the KD of KAT5/Tip60, we observed 161 downregulated genes and 124 upregulated genes commonly affected by KDs of TINTIN members BRD8, MRGBP and MRG15 (Fig. 6A). These numbers change to 253 downregulated and 142 upregulated when MRG15 KD is replaced by MRGX KD (Fig. S3C). Gene ontology term (GO-term) enrichment analyses were performed on those gene sets in order to identify specific biological processes and molecular function pathways in which TINTIN could be implicated (Fig. 6B-C, S3D). We also used RT-qPCR to validate some targets specifically regulated by the TINTIN complex but not the NuA4/TIP60 complex, such as RFX8, HHIP, SYTL5, CD180, which are downregulated by the KDs, and AKT2 which is upregulated. PRRG4 and PCDHB9 are used as control where all KDs were similar to siControl (Fig. 6D).

MRG15, its yeast homolog Eaf3 and MRGBP having already been linked to mRNA splicing processes $(16-18,69)$, we determined if the ratio of alternative transcripts per gene were changed by KDs of TINTIN components. We first compared differential transcript expressions in KDs of BRD8, MRGBP, MRG15/X and KAT5/TIP60 to siControl. Then, we again excluded the transcripts that were significantly changed in KD KAT5/TIP60 (padj $\leq 0.1$ ). The components of the TINTIN complex seem to commonly affect the regulation of only a few alternative transcripts (12 downregulated and 12 upregulated for TINTIN-MRG15, vs 25 down and 18 up for TINTIN-MRGX), even if each KD by itself shows a defect in the expression of much higher numbers of transcripts (Fig. 6E). Overall, these data demonstrate a significant function of the human TINTIN complex, independently of the NuA4/TIP60, in transcription regulation by 
modulating the expression of specific genes (Fig. 6F). We also showed that BRD8 and MRG proteins play also likely important roles in the regulation of some genes from within the NuA4/TIP60 acetyltransferase/remodeling complex or through colocalization on the same target of NUA4/TIP60 at the promoter and TINTIN on the coding region, as we have described in yeast (Fig. 6F)(25).

\section{Discussion}

In this work, we characterized the full interactomes of human MRG domain-containing proteins MRG15 and MRGX, factors that have been implicated in several distinct nuclear processes through association with diverse proteins. These experiments were done as to reflect the most native interactions, avoiding over-expression and when possible, using endogenous proteins as bait. We observed that MRG15 isoforms with long or short CHD and MRGX share the same interactome, such as stable association with the NuA4/TIP60 histone acetyltransferase complex and the Sin3B histone deacetylase/demethylase complex. Interestingly, MRG15 and MRGX are mutually exclusive in their associated complexes. Since MRGX does not possess the H3K36me3binding chromodomain, it will be important to characterize the impact of this difference on the function of their partners. MRG15 knock-out is embryonic lethal in mice, while MRGX knock-out does not lead to any obvious phenotype in development or cell proliferation, which may in part due to some unidirectional compensation mechanism $(19,70,71)$. 
Interestingly, our data show that MRGX and MRG15 are stably associated with the endogenous H3K36me1/me2 methyltransferase ASH1L, in an apparent stoichiometric ratio since its activity cannot be stimulated in vitro by addition of exogenous MRG15 to relieve an auto-inhibitory loop (Fig. 2) (54-57). It will be interesting to study the functional impact of the MRG15 mutations that disrupt its association with endogenous ASH1L in vivo, through genomewide location analysis of ASH1L and H3K36me2. The same mutants also disrupt association with the Sin3B complex. It was shown in yeast that Eaf3 plays a crucial role in the function of the homologous RPD3S complex to deacetylate nucleosomes in the wake of the elongating polymerase to suppress spurious transcription (24). A related function was proposed for the mammalian Sin3B complex $(22,72)$. Thus, it will be interesting to do transcriptomics to analyze if spurious transcription, i.e. cryptic initiation, anti-sense transcription, is detected with the MRG15 mutants. Since Sin3B also contains the KDM5 H3K4me3 demethylase that blocks the spreading of this mark from the TSS region to the body of the genes, it will also be important to verify the impact of the MRG15 mutant on the localization of this histone mark (72).

Most importantly, this study allowed the identification and characterization of a new functional MRG-containing complex, human TINTIN. We discovered a new partner of MRG15, EP400NL, previously dismissed as a probable pseudogene. EP400NL is key to create a BRD8MRGBP-MRG15/X-containing TINTIN complex physically independent of NuA4/TIP60. EP400NL is homologous to the N-terminal region of NuA4/TIP60 scaffold subunit EP400, the interface on which the BRD8-MRGBP-MRG15/X trimer is normally anchored to the complex through BRD8. EP400NL competes with this binding and by doing so free the trimer from NuA4/TIP60, creating TINTIN. Interestingly, the EP400 gene is also known to produce a short splice variant encoding a 
short protein corresponding to EP400NL, which could play a similar role with TINTIN. Importantly, these proteins lack the HSA and SANT domains of EP400 that are required to assemble the NuA4/TIP60 complex $(67,68)$.

Since the yeast TINTIN complex is found on the coding region of active genes and plays a role during transcription elongation, we investigated if human TINTIN also affects gene expression. Indeed, several genes are deregulated in the absence of TINTIN components, independently of NuA4/TIP60 (Fig. 6). Further work will be necessary to better understand the function of TINTIN in mammals. EP400NL is likely an important target to use but, as mentioned above, EP400 short isoforms produced by alternative splicing may play a redundant role. Mapping the precise region of interaction between BRD8 and EP400NL/EP400 may be useful to design better tools to study TINTIN specific function.

Although MRG15 and MRGBP have been proposed to regulate mRNA splicing $(16,17$, 69), we could not find a significant number of alternate transcripts specifically affected by the human TINTIN complex. Our mass spectrometry data also did not detect previously identified partners of MRG15 (PTB) and MRGBP (VEZF) for such function. It is possible that these interactions mostly occur on chromatin, making them difficult to detect in extracts. Independent KDs of MRG15, MRGX and MRGBP do show a larger number of transcripts being misregulated (Fig. 6E). This may be linked instead to the function of the small but abundant MRGBP-MRG15/X dimer that our gel filtration experiment identified (Fig. 4).

In conclusion, this study presented a highly confident native stable interactome of MRG proteins and uncovered a new mammalian complex implicated in gene regulation. It highlights 
the multi-specificity of the MRG domain for protein-protein interactions and associations with distinct protein complexes implicated in several chromatin-based nuclear processes. The presence of H4ac-binding bromodomain and H3K35me3-binding chromodomain in TINTIN also underlines again the cross-talk between transcription and chromatin modifications.

\section{Acknowledgments}

We thank Catherine Lachance, Anahita Lashgari, Alexandre Prudente and Suk Min Jang for work linked to this study and Tatiana Kutateladze for the recombinant ASH1L construct. This work was supported by a grant from the Canadian Institutes of Health Research (FDN-143314) to J.C. J.C. holds the Canada Research Chair in Chromatin Biology and Molecular Epigenetics.

\section{Author contributions}

MD and $C R$ performed experiments. $C B$ and $\mathrm{SH}$ performed bioinformatic analyses. $A D$ and JC supervised and secured funding. MD and JC designed experiments, analyzed the data, and prepared the manuscript.

\section{Conflict of interest}

The authors declare that they have no conflict of interest. 


\section{REFERENCES}

1. Luger K, Mader AW, Richmond RK, Sargent DF, Richmond TJ. 1997. Crystal structure of the nucleosome core particle at $2.8 \mathrm{~A}^{\circ}$ resolution. Nature 389:251-260.

2. Strahl BD, Allis CD. 2000. The language of covalent histone modifications. Nature 403.

3. Torres IO, Fujimori DG. 2015. Functional coupling between writers, erasers and readers of histone and DNA methylation. Current opinion in structural biology 35:68-75.

4. Rothbart SB, Strahl BD. 2014. Interpreting the language of histone and DNA modifications. Biochimica et biophysica acta 1839:627-43.

5. Dawson MA, Kouzarides T, Huntly BJ. 2012. Targeting epigenetic readers in cancer. The New England journal of medicine 367:647-57.

6. Venkatesh S, Workman JL. 2013. Set2 mediated H3 lysine 36 methylation: regulation of transcription elongation and implications in organismal development. Wiley interdisciplinary reviews Developmental biology 2:685-700.

7. Edmunds JW, Mahadevan LC, Clayton AL. 2008. Dynamic histone H3 methylation during gene induction: HYPB/Setd2 mediates all H3K36 trimethylation. The Embo Journal 27:406-420.

8. Kizer KO, Phatnani HP, Shibata Y, Hall H, Greenleaf AL, Strahl BD. 2005. A novel domain in Set2 mediates RNA polymerase II interaction and couples histone H3 K36 methylation with transcript elongation. Molecular and cellular biology 25:3305-16.

9. Lee JS, Shilatifard A. 2007. A site to remember: H3K36 methylation a mark for histone deacetylation. Mutation research 618:130-4.

10. Bannister AJ, Schneider R, Myers FA, Thorne AW, Crane-Robinson C, Kouzarides T. 2005. Spatial distribution of di- and tri-methyl lysine 36 of histone $\mathrm{H} 3$ at active genes. The Journal of biological chemistry 280:17732-6.

11. Vakoc CR, Sachdeva MM, Wang H, Blobel GA. 2006. Profile of histone lysine methylation across transcribed mammalian chromatin. Molecular and cellular biology 26:9185-95.

12. Kolasinska-Zwierz P, Down T, Latorre I, Liu T, Liu XS, Ahringer J. 2009. Differential chromatin marking of introns and expressed exons by H3K36me3. Nature genetics 41:376-81.

13. Wilhelm BT, Marguerat S, Aligianni S, Codlin S, Watt S, Bahler J. 2011. Differential patterns of intronic and exonic DNA regions with respect to RNA polymerase II occupancy, nucleosome density and H3K36me3 marking in fission yeast. Genome biology 12:R82.

14. Spies N, Nielsen CB, Padgett RA, Burge CB. 2009. Biased chromatin signatures around polyadenylation sites and exons. Molecular cell 36:245-54.

15. de Almeida SF, Grosso AR, Koch F, Fenouil R, Carvalho S, Andrade J, Levezinho H, Gut M, Eick D, Gut I, Andrau JC, Ferrier P, Carmo-Fonseca M. 2011. Splicing enhances recruitment of methyltransferase HYPB/Setd2 and methylation of histone H3 Lys36. Nature structural \& molecular biology 18:977-83. 
16. Luco RF, Pan Q, Tominaga K, Blencowe BJ, Pereira-Smith OM, Misteli T. 2010. Regulation of alternative splicing by histone modifications. Science 327:996-1000.

17. Iwamori N, Tominaga K, Sato T, Riehle K, Iwamori T, Ohkawa Y, Coarfa C, Ono E, Matzuk MM. 2016. MRG15 is required for pre-mRNA splicing and spermatogenesis. PNAS:E5408-E5415.

18. Leung CS, Douglass SM, Morselli M, Obusan MB, Pavlyukov MS, Pellegrini M, Johnson TL. 2019. H3K36 Methylation and the Chromodomain Protein Eaf3 Are Required for Proper Cotranscriptional Spliceosome Assembly. Cell reports 27:3760-3769 e4.

19. Chen M, Tominaga K, Pereira-Smith OM. 2010. Emerging role of the MORF/MRG gene family in various biological processes, including aging. Annals of the New York Academy of Sciences 1197:134-41.

20. Xie T, Zmyslowski AM, Zhang Y, Radhakrishnan I. 2015. Structural Basis for Multispecificity of MRG Domains. Structure 23:1049-57.

21. Doyon Y, Cote J. 2004. The highly conserved and multifunctional NuA4 HAT complex. Current opinion in genetics \& development 14:147-54.

22. Jelinic P, Pellegrino J, David G. 2011. A novel mammalian complex containing Sin3B mitigates histone acetylation and RNA polymerase II progression within transcribed loci. Molecular and cellular biology 31:54-62.

23. Hayakawa T, Ohtani Y, Hayakawa N, Shinmyozu K, Saito M, Ishikawa F, Nakayama J. 2007. RBP2 is an MRG15 complex component and down-regulates intragenic histone H3 lysine 4 methylation. Genes Cells 12:811-26.

24. Carrozza MJ, Li B, Florens L, Suganuma T, Swanson SK, Lee KK, Shia WJ, Anderson S, Yates J, Washburn MP, Workman JL. 2005. Histone H3 methylation by Set2 directs deacetylation of coding regions by Rpd3S to suppress spurious intragenic transcription. Cell 123:581-92.

25. Rossetto D, Cramet M, Wang AY, Steunou AL, Lacoste N, Schulze JM, Cote V, MonnetSaksouk J, Piquet S, Nourani A, Kobor MS, Cote J. 2014. Eaf5/7/3 form a functionally independent NuA4 submodule linked to RNA polymerase II-coupled nucleosome recycling. The Embo Journal 33:1397-415.

26. Chen Y, Li J, Dunn S, Xiong S, Chen W, Zhao Y, Chen BB, Mallampalli RK, Zou C. 2014. Histone deacetylase 2 (HDAC2) protein-dependent deacetylation of mortality factor 4like 1 (MORF4L1) protein enhances its homodimerization. The Journal of biological chemistry 289:7092-7098.

27. Sy SM, Huen MS, Chen J. 2009. MRG15 is a novel PALB2-interacting factor involved in homologous recombination. The Journal of biological chemistry 284:21127-31.

28. Ducy M, Sesma-Sanz L, Guitton-Sert L, Lashgari A, Gao Y, Brahiti N, Rodrigue A, Margaillan G, Caron MC, Cote J, Simard J, Masson JY. 2019. The Tumor Suppressor PALB2: Inside Out. Trends in biochemical sciences 44:226-240.

29. Hayakawa T, Zhang F, Hayakawa N, Ohtani Y, Shinmyozu K, Nakayama J, Andreassen PR. 2010. MRG15 binds directly to PALB2 and stimulates homology-directed repair of chromosomal breaks. Journal of cell science 123:1124-30.

30. Bleuyard JY, Fournier M, Nakato R, Couturier AM, Katou Y, Ralf C, Hester SS, Dominguez D, Rhodes D, Humphrey TC, Shirahige K, Esashi F. 2017. MRG15-mediated tethering of PALB2 to unperturbed chromatin protects active genes from genotoxic stress. 
Proceedings of the National Academy of Sciences of the United States of America 114:7671-7676.

31. Wei Y, Tian C, Zhao Y, Liu X, Liu F, Li S, Chen Y, Qiu Y, Feng Z, Chen L, Zhou T, Ren X, Feng C, Liu Y, Yu W, Ying H, Ding Q. 2020. MRG15 orchestrates rhythmic epigenomic remodelling and controls hepatic lipid metabolism. Nat Metab 2:447-460.

32. Lalonde ME, Avvakumov N, Glass KC, Joncas FH, Saksouk N, Holliday M, Paquet E, Yan K, Tong Q, Klein BJ, Tan S, Yang XJ, Kutateladze TG, Cote J. 2013. Exchange of associated factors directs a switch in HBO1 acetyltransferase histone tail specificity. Genes \& development 27:2009-24.

33. Saksouk N, Avvakumov N, Champagne KS, Hung T, Doyon Y, Cayrou C, Paquet E, Ullah M, Landry AJ, Cote V, Yang XJ, Gozani O, Kutateladze TG, Cote J. 2009. HBO1 HAT complexes target chromatin throughout gene coding regions via multiple PHD finger interactions with histone $\mathrm{H} 3$ tail. Molecular cell 33:257-65.

34. Dalvai M, Loehr J, Jacquet K, Huard CC, Roques C, Herst P, Cote J, Doyon Y. 2015. A Scalable Genome-Editing-Based Approach for Mapping Multiprotein Complexes in Human Cells. Cell reports 13:621-633.

35. Agudelo D, Duringer A, Bozoyan L, Huard CC, Carter S, Loehr J, Synodinou D, Drouin M, Salsman J, Dellaire G, Laganiere J, Doyon Y. 2017. Marker-free coselection for CRISPRdriven genome editing in human cells. Nature methods 14:615-620.

36. Nesvizhskii Al, Keller A, Kolker E, Aebersold R. 2003. A statistical model for identifying proteins by tandem mass spectrometry. Anal Chem 75:4646-58.

37. Li H. 2018. Minimap2: pairwise alignment for nucleotide sequences. Bioinformatics 34:3094-3100.

38. Liao Y, Smyth GK, Shi W. 2014. featureCounts: an efficient general purpose program for assigning sequence reads to genomic features. Bioinformatics 30:923-30.

39. Robinson MD, McCarthy DJ, Smyth GK. 2010. edgeR: a Bioconductor package for differential expression analysis of digital gene expression data. Bioinformatics 26:13940.

40. Chen S, Zhou Y, Chen Y, Gu J. 2018. fastp: an ultra-fast all-in-one FASTQ preprocessor. Bioinformatics 34:i884-i890.

41. de Sena Brandine G, Smith A, D. 2021. Falco: high-speed FastQC emulation for quality control of sequencing data. f1000research 8:1874.

42. Ewels $P$, Magnusson M, Lundin S, Kaller M. 2016. MultiQC: summarize analysis results for multiple tools and samples in a single report. Bioinformatics 32:3047-8.

43. Bray NL, Pimentel H, Melsted P, Pachter L. 2016. Near-optimal probabilistic RNA-seq quantification. Nature biotechnology 34:525-7.

44. Kirby KN, Gerlanc D. 2013. BootES: an R package for bootstrap confidence intervals on effect sizes. Behavior research methods 45:905-27.

45. Love MI, Huber W, Anders S. 2014. Moderated estimation of fold change and dispersion for RNA-seq data with DESeq2. Genome biology 15:550.

46. Ruan C, Lee $\mathrm{CH}$, Cui H, Li S, Li B. 2015. Nucleosome contact triggers conformational changes of Rpd3S driving high-affinity H3K36me nucleosome engagement. Cell reports 10:204-15. 
47. Venkatesh S, Smolle M, Li H, Gogol MM, Saint M, Kumar S, Natarajan K, Workman JL. 2012. Set2 methylation of histone $H 3$ lysine 36 suppresses histone exchange on transcribed genes. Nature 489:452-5.

48. Zhang P, Du J, Sun B, Dong X, Xu G, Zhou J, Huang Q, Liu Q, Hao Q, Ding J. 2006. Structure of human MRG15 chromo domain and its binding to Lys36-methylated histone H3. Nucleic acids research 34:6621-8.

49. Doyon Y, Cote J. 2016. Preparation and Analysis of Native Chromatin-Modifying Complexes. Methods Enzymol 573:303-18.

50. Larance M, Kirkwood KJ, Xirodimas DP, Lundberg E, Uhlen M, Lamond Al. 2012. Characterization of MRFAP1 turnover and interactions downstream of the NEDD8 pathway. Molecular \& cellular proteomics : MCP 11:M111 014407.

51. Zhu L, Li Q, Wong SH, Huang M, Klein BJ, Shen J, Ikenouye L, Onishi M, Schneidawind D, Buechele C, Hansen L, Duque-Afonso J, Zhu F, Martin GM, Gozani O, Majeti R, Kutateladze TG, Cleary ML. 2016. ASH1L Links Histone H3 Lysine 36 Dimethylation to MLL Leukemia. Cancer discovery 6:770-83.

52. An S, Yeo KJ, Jeon YH, Song JJ. 2011. Crystal structure of the human histone methyltransferase ASH1L catalytic domain and its implications for the regulatory mechanism. The Journal of biological chemistry 286:8369-8374.

53. Balbo Pogliano C, Gatti M, Ruthemann P, Garajova Z, Penengo L, Naegeli H. 2017. ASH1L histone methyltransferase regulates the handoff between damage recognition factors in global-genome nucleotide excision repair. Nature communications 8:1333.

54. Huang C, Yang F, Zhang Z, Zhang J, Cai G, Li L, Zheng Y, Chen S, Xi R, Zhu B. 2017. Mrg15 stimulates Ash1 H3K36 methyltransferase activity and facilitates Ash1 Trithorax group protein function in Drosophila. Nature communications 8:1649.

55. Schmahling S, Meiler A, Lee Y, Mohammed A, Finkl K, Tauscher K, Israel L, Wirth M, Philippou-Massier J, Blum H, Habermann B, Imhof A, Song JJ, Muller J. 2018. Regulation and function of H3K36 di-methylation by the trithorax-group protein complex AMC. Development 145.

56. Lee Y, Yoon E, Cho S, Schmahling S, Muller J, Song JJ. 2019. Structural Basis of MRG15Mediated Activation of the ASH1L Histone Methyltransferase by Releasing an Autoinhibitory Loop. Structure 27:846-852 e3.

57. Hou P, Huang C, Liu CP, Yang N, Yu T, Yin Y, Zhu B, Xu RM. 2019. Structural Insights into Stimulation of Ash1L's H3K36 Methyltransferase Activity through Mrg15 Binding. Structure 27:837-845 e3.

58. Hu X, Harvey SE, Zheng R, Lyu J, Grzeskowiak CL, Powell E, Piwnica-Worms H, Scott KL, Cheng C. 2020. The RNA-binding protein AKAP8 suppresses tumor metastasis by antagonizing EMT-associated alternative splicing. Nature communications 11:486.

59. Xie T, Graveline R, Kumar GS, Zhang Y, Krishnan A, David G, Radhakrishnan I. 2012. Structural basis for molecular interactions involving MRG domains: implications in chromatin biology. Structure 20:151-60.

60. Wu J, Chen Y, Lu LY, Wu Y, Paulsen MT, Ljungman M, Ferguson DO, Yu X. 2011. Chfr and RNF8 synergistically regulate ATM activation. Nature structural \& molecular biology 18:761-8. 
61. Jacquet K, Fradet-Turcotte A, Avvakumov N, Lambert JP, Roques C, Pandita RK, Paquet E, Herst P, Gingras AC, Pandita TK, Legube G, Doyon Y, Durocher D, Cote J. 2016. The TIP60 Complex Regulates Bivalent Chromatin Recognition by 53BP1 through Direct H4K20me Binding and H2AK15 Acetylation. Molecular cell 62:409-421.

62. Bassi C, Li YT, Khu K, Mateo F, Baniasadi PS, Elia A, Mason J, Stambolic V, Pujana MA, Mak TW, Gorrini C. 2016. The acetyltransferase Tip60 contributes to mammary tumorigenesis by modulating DNA repair. Cell death and differentiation 23:1198-208.

63. Li ML, Jiang Q, Bhanu NV, Wu J, Li W, Garcia BA, Greenberg RA. 2019. Phosphorylation of TIP60 Suppresses 53BP1 Localization at DNA Damage Sites. Molecular and cellular biology 39.

64. Bhat W, Ahmad S, Cote J. 2015. TINTIN, at the interface of chromatin, transcription elongation, and mRNA processing. RNA biology 12:486-9.

65. Pradhan SK, Su T, Yen L, Jacquet K, Huang C, Cote J, Kurdistani SK, Carey MF. 2016. EP400 Deposits H3.3 into Promoters and Enhancers during Gene Activation. Mol Cell 61:27-38.

66. Yamaguchi K, Sakai M, Shimokawa T, Yamada Y, Nakamura Y, Furukawa Y. 2010. C20orf20 (MRG-binding protein) as a potential therapeutic target for colorectal cancer. British journal of cancer 102:325-31.

67. Setiaputra D, Ahmad S, Dalwadi U, Steunou AL, Lu S, Ross JD, Dong MQ, Cote J, Yip CK. 2018. Molecular Architecture of the Essential Yeast Histone Acetyltransferase Complex NuA4 Redefines Its Multimodularity. Mol Cell Biol 38.

68. Wang X, Ahmad S, Zhang Z, Cote J, Cai G. 2018. Architecture of the Saccharomyces cerevisiae NuA4/TIP60 complex. Nat Commun 9:1147.

69. Gowher H, Brick K, Camerini-Otero DR, Felsenfeld G. 2012. Vezf1 protein binding sites genome-wide are associated with pausing of elongating RNA polymerase II. Proc Natl Acad Sci U S A 109(7):2370-5.

70. Tominaga K, Matzuk MM, Pereira-Smith OM. 2005. MrgX is not essential for cell growth and development in the mouse. Molecular and cellular biology 25:4873-80.

71. Tominaga K, Kirtane B, Jackson JG, Ikeno Y, Ikeda T, Hawks C, Smith JR, Matzuk MM, Pereira-Smith OM. 2005. MRG15 regulates embryonic development and cell proliferation. Mol Cell Biol 25:2924-37.

72. Xie L, Pelz C, Wang W, Bashar A, Varlamova O, Shadle S, Impey S. 2011. KDM5B regulates embryonic stem cell self-renewal and represses cryptic intragenic transcription. EMBO J 30:1473-84. 


\section{FIGURE LEGENDS}

Figure 1. The interactome of MRG proteins highlights the association with several distinct complexes.

(A) Schematic representation of MRG15 spliced variants, MRGX, and the yeast Eaf3 functional domains.

(B) Short chromodomain MRG15 binds preferentially H3K36me3 in vitro. Recombinant GST-tagged MRG15 isoforms or GST or beads were incubated with LON followed by washes and western blotting. Anti-H4 and anti-H3K79me3 are used as control.

(C) 4-12\% SDS-page of 3xFlag-2xStrep elutions of indicated purification from K562 cells were analyzed by silver staining. MRGX and MRG15 spliced variants bind the acetyltransferase NuA4/TIP60 complex. Subunits were identified by mass spectrometry (Table S1).

(D-E) Purified complexes from C) were analyzed by western blot with the indicated antibodies to confirm the equivalent presence of known subunits of the NuA4/TIP60 complex (D) and the other known interactors of MRG proteins (E) (* non-specific band).

Figure 2. Endogenous ASH1L is stably associated with MRG proteins.

(A) Purification of endogenous ASH1L from K562 cells modified by CRISPR/Cas9 system to add 3xFlag 2xStrep. The elution was analyzed on 4-12\% SDS-PAGE followed by silver staining.

(B) Purified ASH1L from A) was analyzed by western blot with the indicated antibodies to confirm the interaction with ASH1L and its interactors such as MRG proteins and AKAP8.

(C) In vitro histone methyltransferase assay performed with recombinant ASH1L (aa2040-2634)pGEX6P2 (recAHS1L) and strep elution from endogenous ASH1L (endoASH1L). The graph shows the scintillation counts of the liquid assays with $3 \mathrm{H} \mathrm{S}$ - adenosyl methionine (SAM) with native short oligonucleosomes (SON). An empty vector pGEX6P2 and a mock cell line were used as control and subtracted from final counts. Error bars represent the range of two technical replicates.

Figure 3. Structure-based mutations can differentially affect specific MRG15-containing complexes.

(A) Schematic representation of W172A Y235A MRG15 mutant leading only MRGBP interaction, and W78A F105A MRGBP mutant preventing MRG15 interaction. 
(B) 4-12\% SDS-page of 3xFlag-2xStrep elutions of indicated purification from K562 cells were analyzed by silver staining. Strep elutions were analyzed by mass spectrometry in total spectrum count (Table 4).

(C) Purified complexes from (B) were analyzed by western blot with the indicated antibodies (* nonspecific band).

Figure 4. Identification of the TINTIN complex in human cells, composed of BRD8-MRGBP-MRG15/X and new subunit EP400NL.

(A) Purification of native NuA4/TIP60 complex from K562 cells. Strep elutions of indicated purifications were analyzed on 4-12\% SDS-PAGE followed by silver staining. MRGBP and spliced variants of BRD8 (1BRD, one bromodomain, 2BRD, two bromodomains, and CRISPR for N-term tagged BRD8) are linked to NuA4/TIP60 complex.

(B) Western blots of purified complexes in (A) confirmed the interaction with NuA4/TIP60 complex and the new subunit EP400NL.

(C) Western blots of gel filtration (FPLC) from fractions 17 to 33 representing annotated complex from flag elutions of EPC1, BRD8, and MRGBP AAVS1 K562 cell lines.

(D) 4-12\% SDS-PAGE followed by silver staining of annotated fractions showing NuA4/TIP60 complex (17), TINTIN complex (23), and dimer MRGBP/MRG15 or MRGX (33) from flag elutions of BRD8, MRGBP, and EPC1.

Figure 5. Endogenous EP400NL isolates TINTIN through an interaction with BRD8.

(A) 3xFlag-2xStrep elutions of Q6ZTU2-5 (AAVS1) or endogenous (CRISPR) purified EP400NL from K562 cells analyzed by silver staining.

(B) Purified complexes from (A) were analyzed by western blot with the indicated antibodies to confirm the interaction with BRD8, MRGBP, and MRG15/X representing the human TINTIN complex.

(C) BRD8 interacts with the N-term region of EP400NL in vitro. Recombinant His-tagged BRD8 was incubated with GST fusion proteins on beads followed by washes and western blotting. 
(D) Schematic representation of BRD8-MRGBP-MRG15/X that can bind EP400 to form NuA4/TIP60 complex or the new subunit EP400NL to form TINTIN complex.

\section{Figure 6. Human TINTIN is implicated in the expression of specific genes.}

(A) 161 genes are commonly downregulated (left) and 124 are upregulated in KDs of BRD8, MRGBP, and MRG15 but not in KD of TIP60, in U2OS cells. We kept the genes with high changes in expression, using a cutoff of 2-fold difference was applied to the Log2(fold change) values between the selected KDs and control (siLuc).

(B) and (C) Gene ontology analysis for downregulated (D) and upregulated genes (C) showing a significant enrichment (pValue <0.01) using DAVID 6.8.

(D) RT-qPCR to validate target genes of TINTIN. RFX8, HHIP, SYTL5, and CD180 are found downregulated, and AKT2 is upregulated in KD TINTIN subunits. PRRG4 and PCDHB9 are used as control. Values represent means relative to control (siLuc). Error bars represent the range from two biological replicates.

(E) Venn diagrams of downregulated (left) and upregulated (right) transcripts, specifically regulated by KDBRD8, MRGBP, MRG15, or MRGX after exclusion of transcripts regulated by KDKAT5/TIP60, using a cutoff of 2-fold difference. siLuciferase was used as control. Two replicates of each KD were performed in U2OS cells.

(F) BRD8 brings MRG proteins into the acetyltransferase NuA4/TIP60 complex due to its direct interaction with the EP400-N-terminal fraction. These subunits are important for gene expressions of specific targets. Furthermore, those subunits form a new submodule, called TINTIN, when BRD8 interacts with a new factor, EP400NL. TINTIN is also important for transcription regulation of specific genes. 
bioRxiv preprint doi: https://doi.org/10.1101/2021.08.11.456009; this version posted August 12, 2021. The copyright holder for this preprint (which was not certified by peer review) is the author/funder, who has granted bioRxiv a license to display the preprint in perpetuity. It is made available under aCC-BY-NC-ND 4.0 International license.

\section{Devoucoux Figure 1}

A

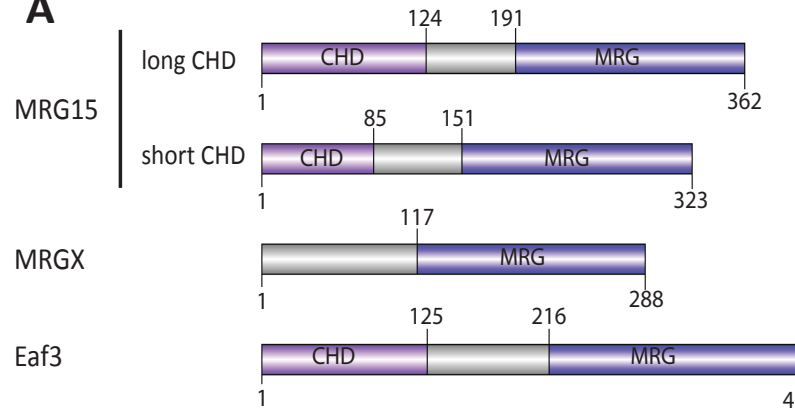

C

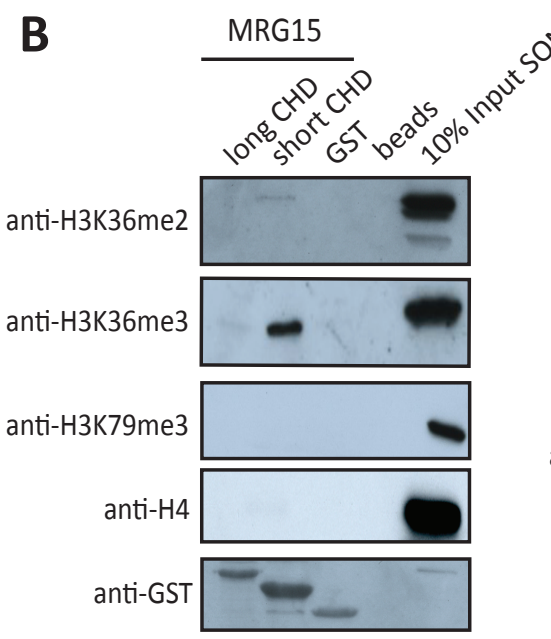

MRGX-3F-2S MRG15-3F-2S

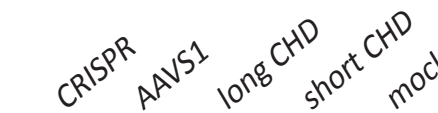

TRAPP/EP400 -

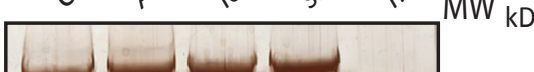

200

116.3

97.4

EPC1/2

DMAP1/KAT5/ING3 -

RUVBL1/2

Baf53a/Vps72/
MRG15/Actin

MRGX
MRGBP

Gas41/MEAF6

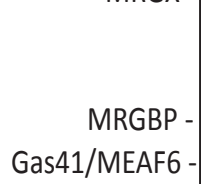

36.5

31
D

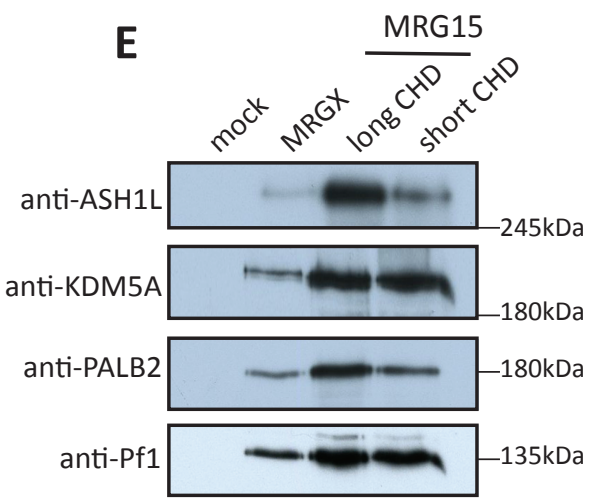

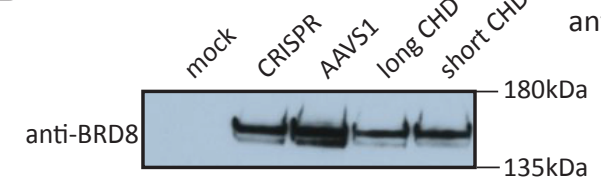
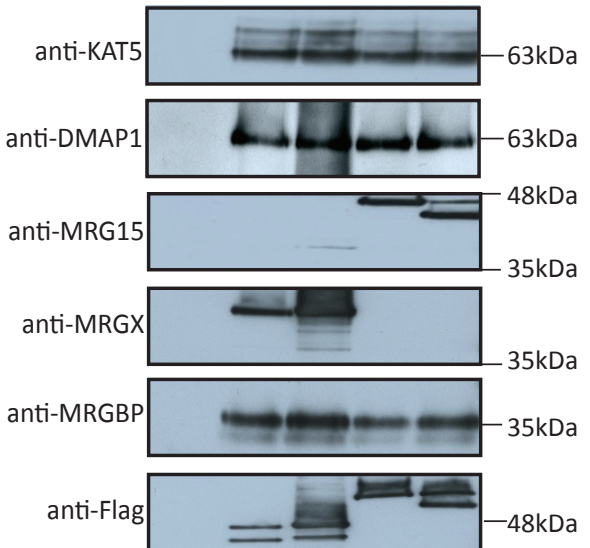

21.5 
A

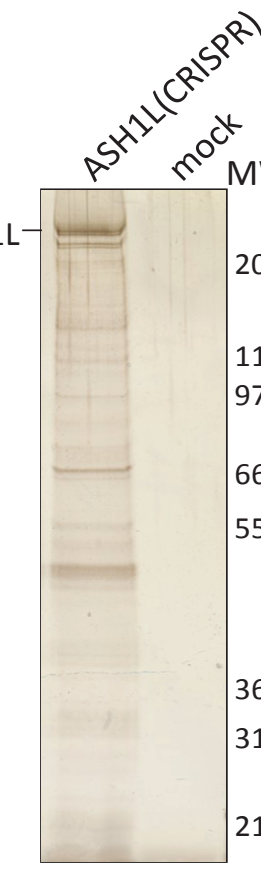

31

B

MW kDa

200

116.3

97.4

66.3

55.4

36.5

21.5

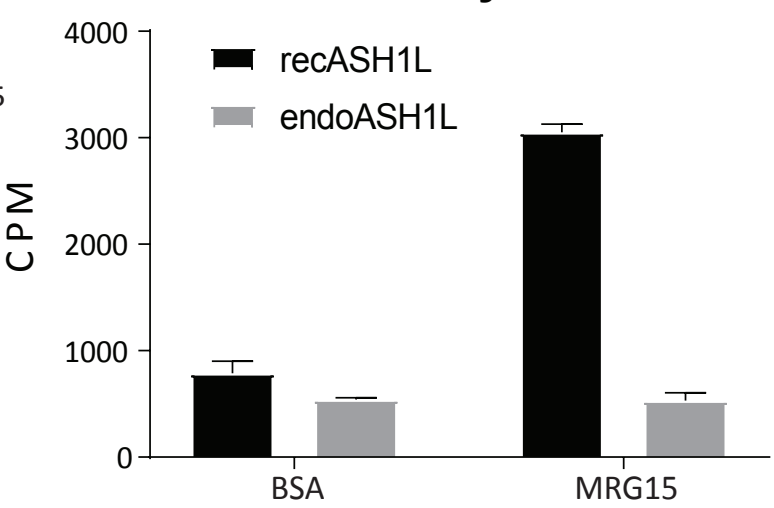


A
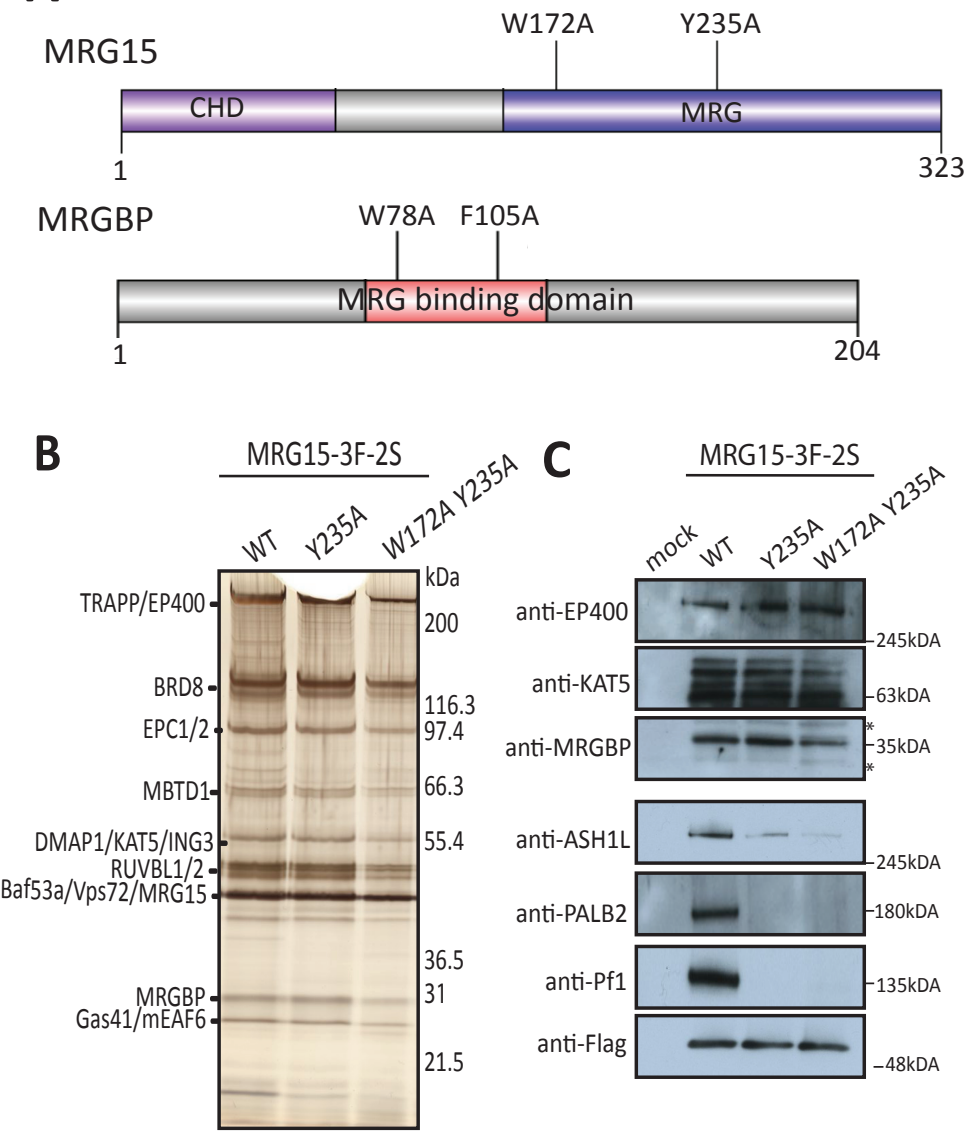

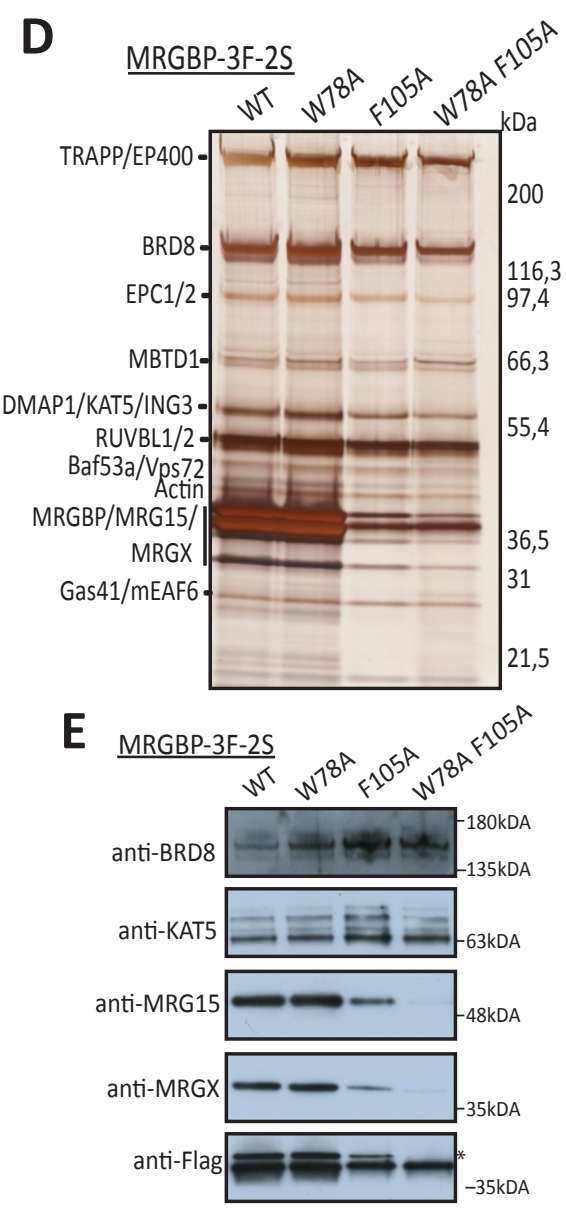


bioRxiv preprint doi: https://doi.org/10.1101/2021.08.11.456009; this version posted August 12, 2021. The copyright holder for this preprint (which was not certified by peer review) is the author/funder, who has granted bioRxiv a license to display the preprint in perpetuity. It is made available under aCC-BY-NC-ND 4.0 International license.

\section{Devoucoux Figure 4}

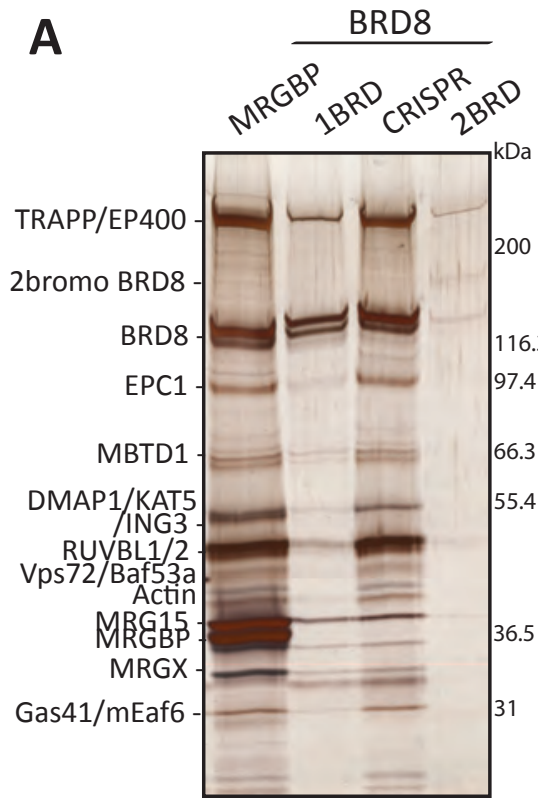

C

EPC1

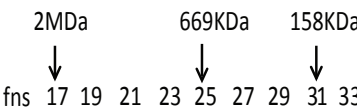
anti-EP400 Frat

\section{EP400NL}

anti-BRD8

anti-KAT5

anti-DMAP1

anti- MRG15 -

$$
\text { anti-MRGX }
$$

anti-MRGBP

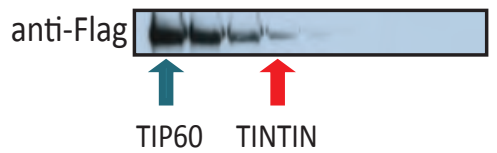

B

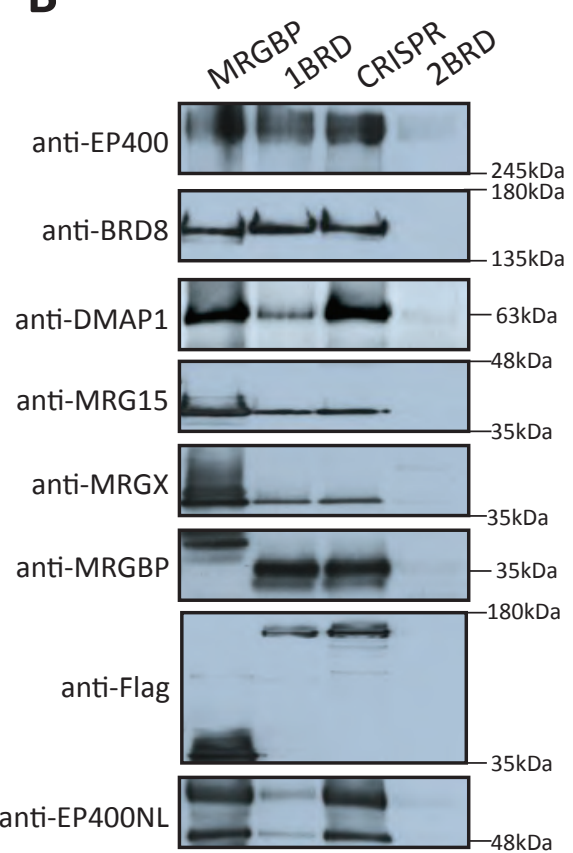

D

\begin{tabular}{|c|c|}
\hline BRD8 & MRGB \\
\hline
\end{tabular}
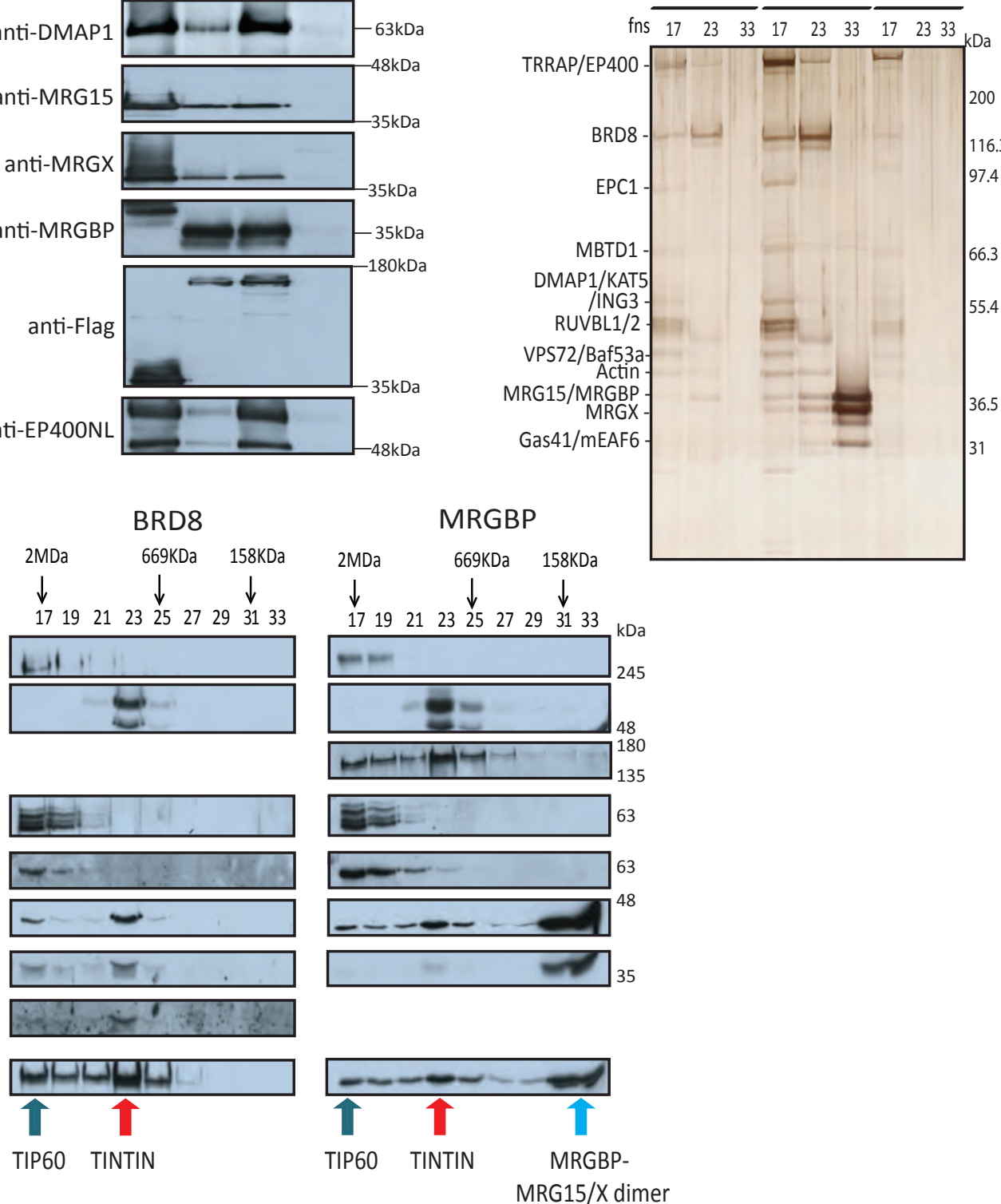
A

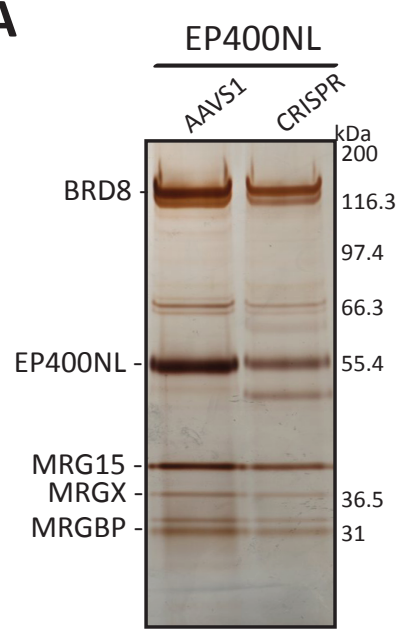

C Pulldown

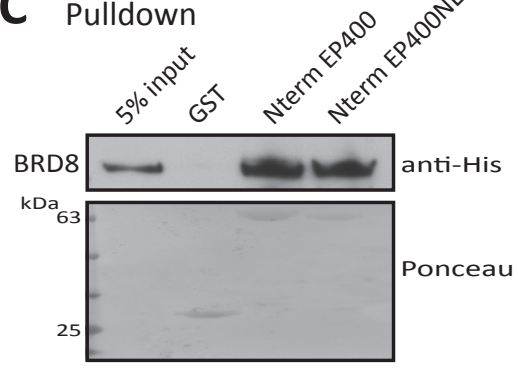

B

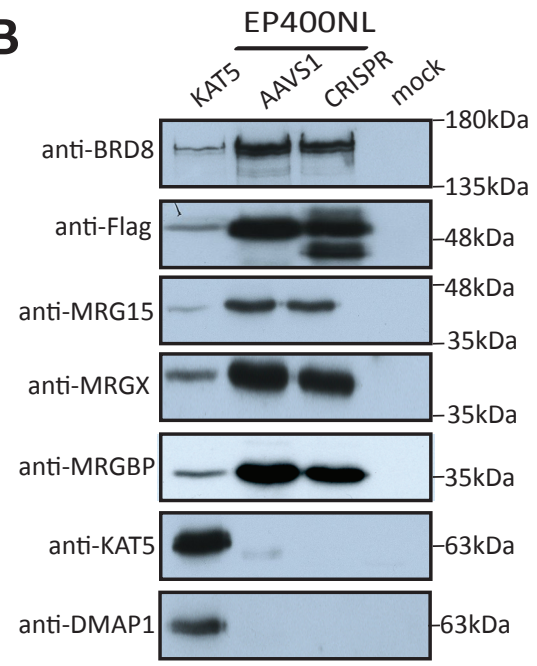

D NuA4/TIP60 complex

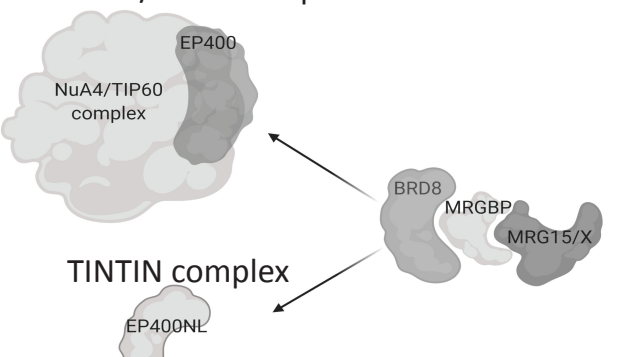




\section{Downregulated genes}

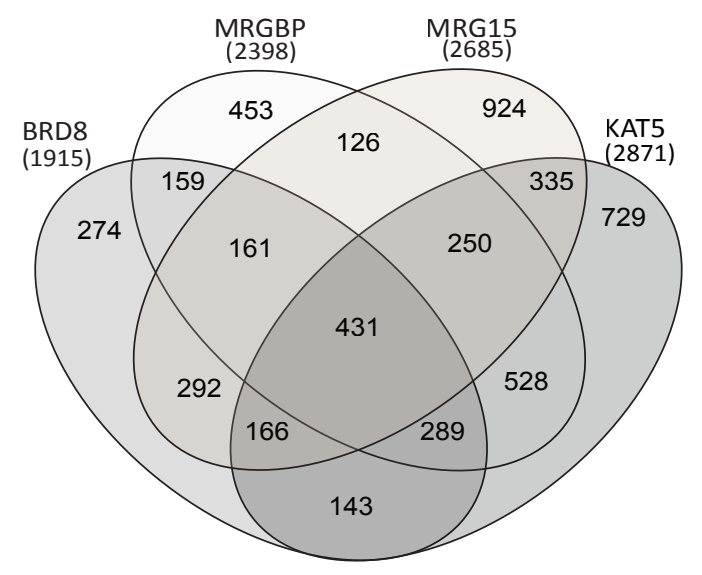

B

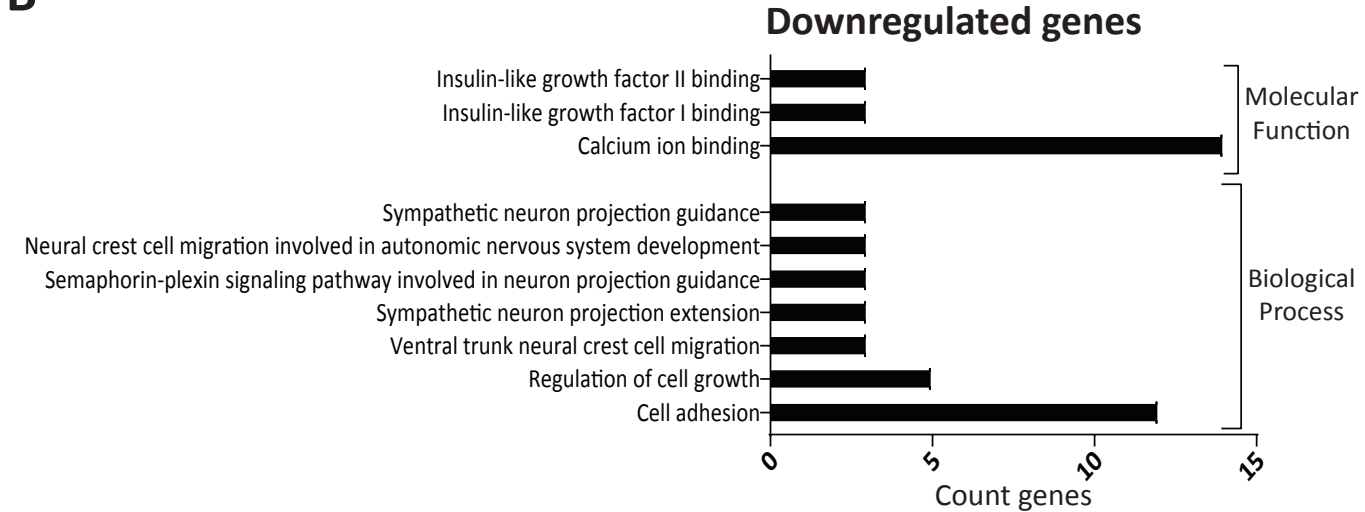

Devoucoux Figure 6

C

Upregulated genes

Creatine transmembrane transporter activity

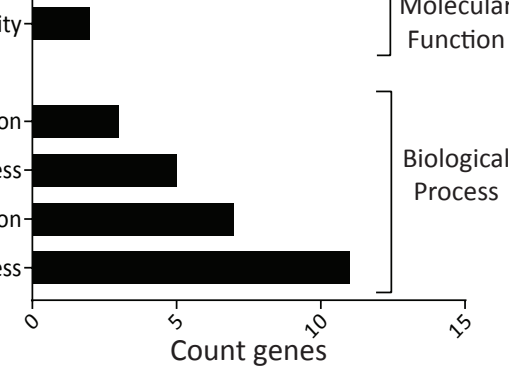

D

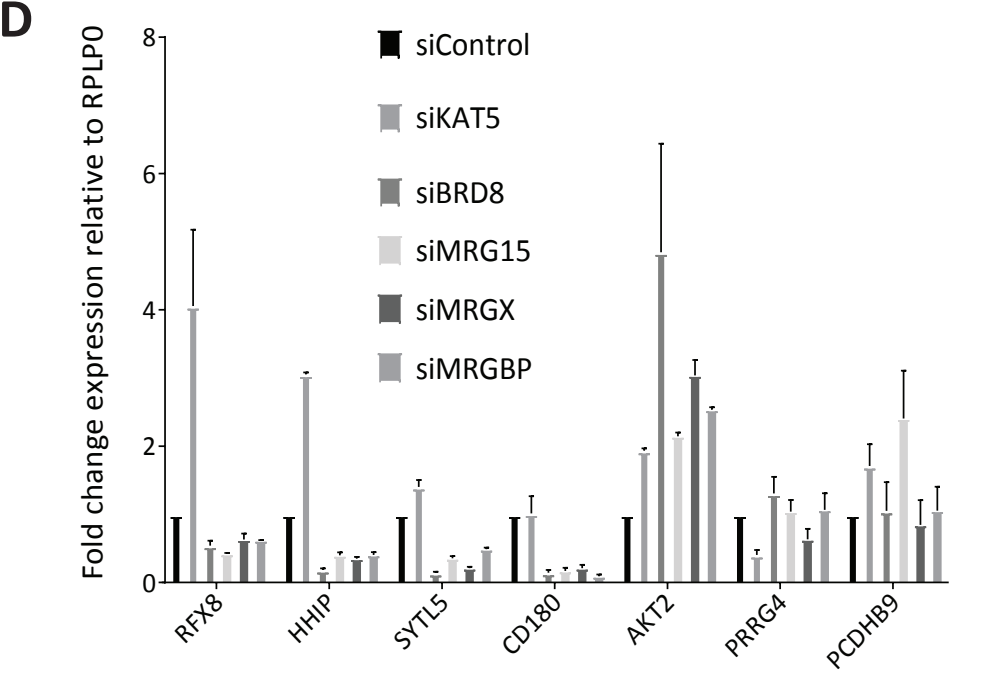

ucose metabolic process

Cell-cell adhesio

Apoptotic process

Count genes

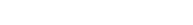

Negative regulation of osteoclast differentiation

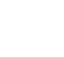

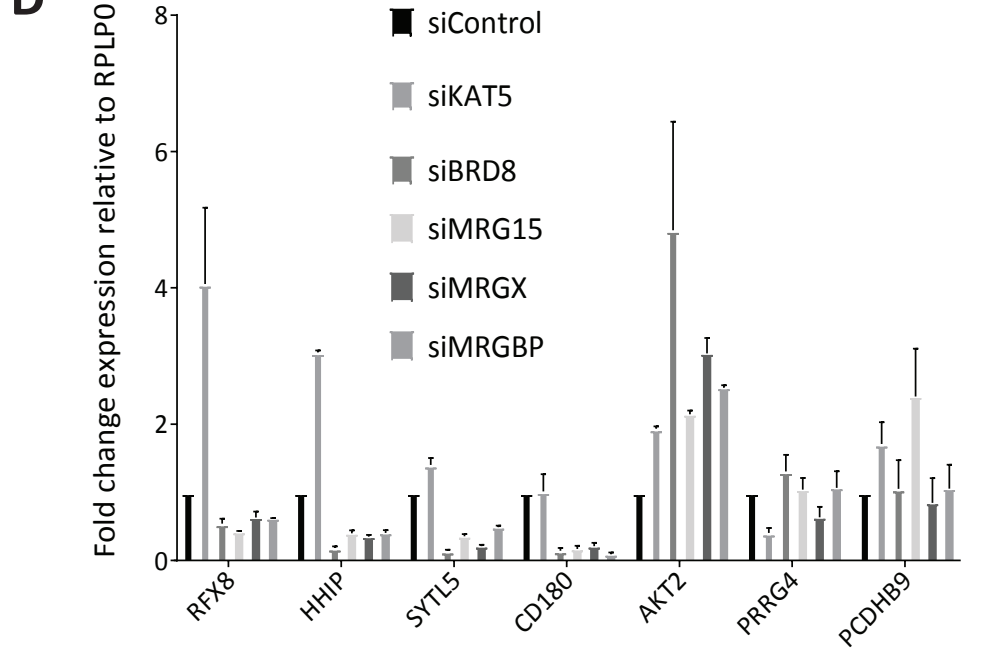

E Downregulated genes

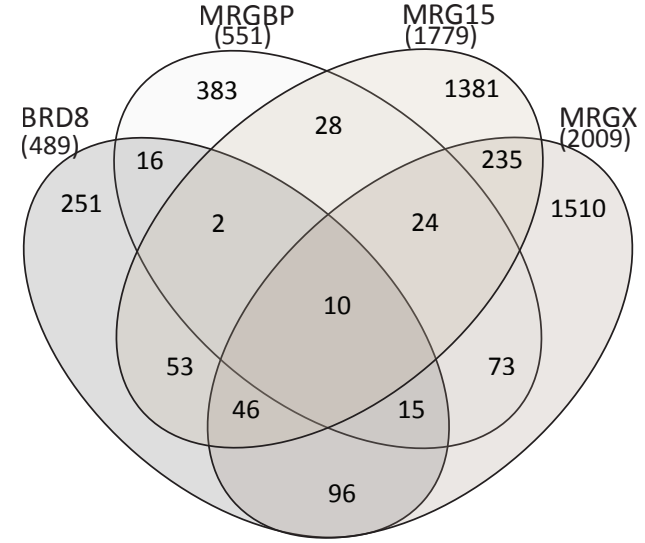

Upregulated genes

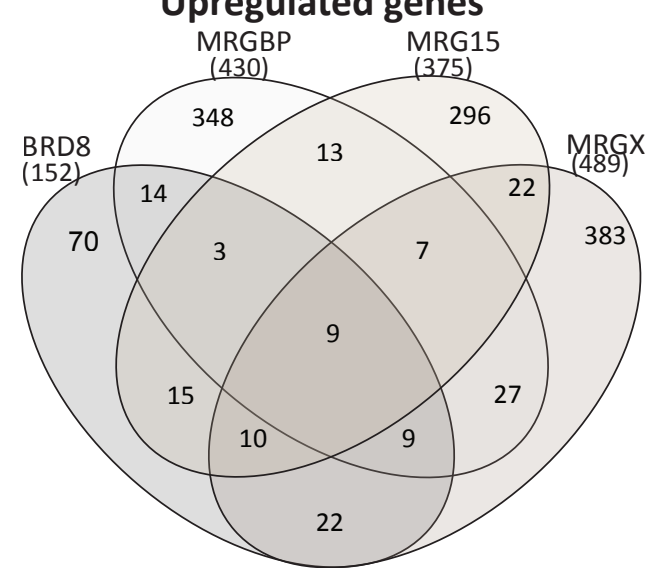

$\mathbf{F}$

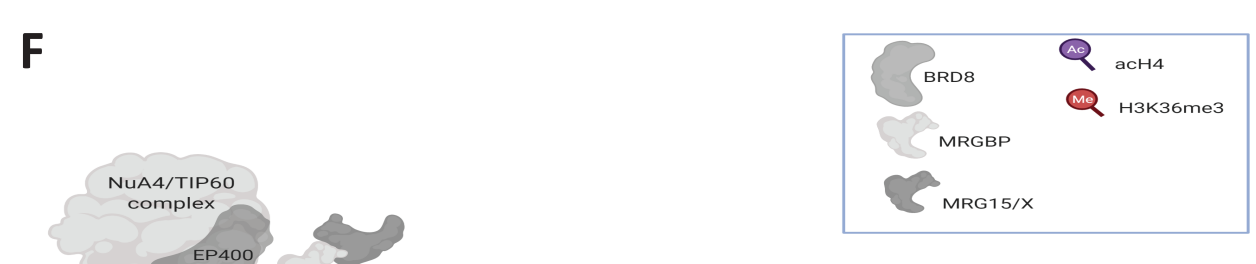

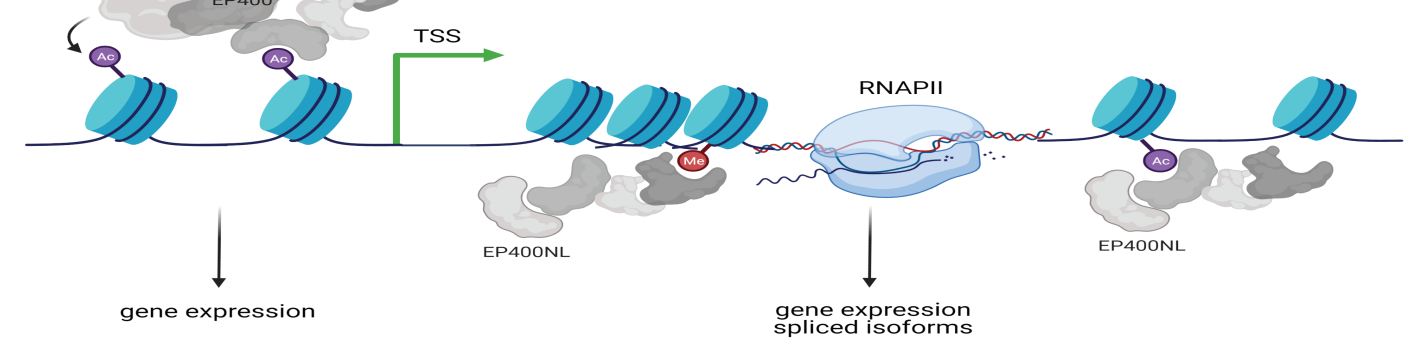


Table S1. Mass spectrometry analysis of proteins that copurified with MRGX, MRG15 long and short CHD from K562 nuclear extracts and after DNA damage (NCS) (Total spectral counts), Related to Fig. 1.

\begin{tabular}{|c|c|c|c|c|c|}
\hline \multirow[b]{2}{*}{ NuA4/Tip60 } & \multirow[b]{2}{*}{ MW } & \multirow[b]{2}{*}{ Mock } & \multirow[b]{2}{*}{ MRGX } & \multicolumn{2}{|c|}{ MRG15 } \\
\hline & & & & long CHD & Short CHD \\
\hline TRRAP & $436 \mathrm{kDa}$ & 0 & 174 & 184 & 392 \\
\hline EP400 & 336 kDa & 0 & 175 & 143 & 301 \\
\hline BRD8 & 97 kDa & 0 & 85 & 80 & 138 \\
\hline EPC1 & 91 kDa & 0 & 22 & 16 & 36 \\
\hline EPC2 & 91 kDa & 0 & 21 & 28 & 59 \\
\hline MBTD1 & $71 \mathrm{kDa}$ & 0 & 11 & 21 & 35 \\
\hline KAT5/TIP60 & $53 \mathrm{kDa}$ & 0 & 11 & 9 & 32 \\
\hline DMAP1 & $53 \mathrm{kDa}$ & 0 & 37 & 27 & 45 \\
\hline RUVBL2 & $51 \mathrm{kDa}$ & 0 & 61 & 58 & 93 \\
\hline RUVBL1 & $50 \mathrm{kDa}$ & 0 & 53 & 49 & 103 \\
\hline Baf53a & $47 \mathrm{kDa}$ & 0 & 37 & 28 & 47 \\
\hline ING3 & $45 \mathrm{kDa}$ & 0 & 9 & 11 & 31 \\
\hline ACTB & $42 \mathrm{kDa}$ & 0 & 30 & 30 & 38 \\
\hline Vps72 & $42 \mathrm{kDa}$ & 0 & 8 & 10 & 23 \\
\hline MRG15 & $40 \mathrm{kDa}$ & 0 & 17 & 54 & 152 \\
\hline MRGX & $32 \mathrm{kDa}$ & 0 & 138 & 6 & 0 \\
\hline GAS41 & $27 \mathrm{kDa}$ & 0 & 20 & 17 & 21 \\
\hline MRGBP & $22 \mathrm{kDa}$ & 0 & 21 & 9 & 34 \\
\hline MEAF6 & $22 \mathrm{kDa}$ & 0 & 5 & 7 & 10 \\
\hline $\mathrm{H} 2 \mathrm{~B}$ & 14 kDa & 0 & 2 & 2 & 8 \\
\hline
\end{tabular}

\begin{tabular}{|r|}
\hline \multicolumn{1}{|c|}{ MRG15+NCS } \\
\hline \multicolumn{2}{|c|}{ short CHD } \\
\hline 547 \\
\hline 348 \\
\hline 162 \\
\hline 53 \\
\hline 76 \\
\hline 38 \\
\hline 45 \\
\hline 51 \\
\hline 106 \\
\hline 103 \\
\hline 60 \\
\hline 39 \\
\hline 47 \\
\hline 21 \\
\hline 152 \\
\hline 0 \\
\hline 22 \\
\hline 42 \\
\hline 8 \\
\hline 8 \\
\hline
\end{tabular}

\begin{tabular}{|l|l|r|r|r|r|}
\hline \multicolumn{1}{|c|}{ Sin3B } & \multicolumn{1}{c|}{ MW } & \multicolumn{1}{c|}{ Mock } & \multicolumn{1}{c|}{ MRGX } & long CHD & \multicolumn{1}{c|}{ Short CHD } \\
\hline KDM5A & $196 \mathrm{kDa}$ & 0 & 3 & 9 & 29 \\
\hline Sin3B & $129 \mathrm{kDa}$ & 0 & 1 & 7 & 26 \\
\hline Pf1/PHF12 & $110 \mathrm{kDa}$ & 0 & 8 & 9 & 27 \\
\hline HDAC1 & $52 \mathrm{kDa}$ & 0 & 0 & 0 & 3 \\
\hline RBBP7 & $47 \mathrm{kDa}$ & 0 & 1 & 2 & 0 \\
\hline EMSY & $131 \mathrm{kDa}$ & 0 & 14 & 23 & 48 \\
\hline
\end{tabular}

\begin{tabular}{|r|}
\hline \multicolumn{1}{|c|}{ short CHD } \\
\hline 36 \\
\hline 39 \\
\hline 41 \\
\hline 7 \\
\hline 0 \\
\hline 46 \\
\hline
\end{tabular}

\begin{tabular}{|l|l|r|r|r|r|}
\hline \multicolumn{1}{|c|}{ Others } & \multicolumn{1}{c|}{ MW } & \multicolumn{1}{c|}{ Mock } & MRGX & long CHD & Short CHD \\
\hline EP400NL & $45 \mathrm{kDa}$ & 0 & 32 & 21 & 67 \\
\hline BRCA2 & $384 \mathrm{kDa}$ & 0 & 8 & 16 & 60 \\
\hline PALB2 & $131 \mathrm{kDa}$ & 0 & 5 & 3 & 22 \\
\hline ASH1L & $332 \mathrm{kDa}$ & 0 & 0 & 2 & 27 \\
\hline MRFAP1 & $15 \mathrm{kDa}$ & 0 & 12 & 3 & 6 \\
\hline
\end{tabular}

short CHD

\begin{tabular}{|r|}
\hline 73 \\
\hline 83 \\
\hline 22 \\
\hline 33 \\
\hline 2 \\
\hline
\end{tabular}


bioRxiv preprint doi: https://doi.org/10.1101/2021.08.11.456009; this version posted August 12, 2021. The copyright holder for this preprint (which was not certified by peer review) is the author/funder, who has granted bioRxiv a license to display the preprint in perpetuity. It is made available under aCC-BY-NC-ND 4.0 International license.

Table S2. Mass spectrometry analysis of endogenous ASH1L purified from K562 cells (total spectral counts). Related to Figure 2.

\begin{tabular}{|l|l|r|}
\hline Identified Proteins & \multicolumn{1}{|c|}{ MW } & ASH1L \\
\hline ASH1L & $332 \mathrm{kDa}$ & 222 \\
\hline MRG15 & $40 \mathrm{kDa}$ & 17 \\
\hline MRGX & $32 \mathrm{kDa}$ & 10 \\
\hline RBBP4/ NURF55 & $48 \mathrm{kDa}$ & 12 \\
\hline AKAP8 & $76 \mathrm{kDa}$ & 13 \\
\hline AKAP8L & $72 \mathrm{kDa}$ & 7 \\
\hline KMT2A & $432 \mathrm{kDa}$ & 4 \\
\hline HDAC1 & $55 \mathrm{kDa}$ & 7 \\
\hline
\end{tabular}


Table S3. Mass spectrometry analysis of MRG15 WT versus mutant interactomes purified from K562 cells through MRG15-3xFlag 2xStrep integrated at AAVS1 (total spectral counts). Related to Figure 3.

\begin{tabular}{|c|c|c|c|c|c|}
\hline & \multirow[b]{2}{*}{$\begin{array}{l}\text { Identified } \\
\text { proteins }\end{array}$} & \multirow[b]{2}{*}{ MW } & \multicolumn{3}{|c|}{ MRG15 } \\
\hline & & & WT & Y235A & $\begin{array}{l}\text { W172A } \\
\text { Y235A }\end{array}$ \\
\hline \multirow{19}{*}{$\begin{array}{l}\text { NuA4/TIP60 } \\
\text { complex }\end{array}$} & TRRAP & $436 \mathrm{kDa}$ & 94 & 25 & 14 \\
\hline & EP400 & $343 \mathrm{kDa}$ & 183 & 159 & 52 \\
\hline & BRD8 & 103 kDa & 73 & 47 & 23 \\
\hline & EPC2 & 91 kDa & 38 & 20 & 11 \\
\hline & EPC1 & $91 \mathrm{kDa}$ & 24 & 16 & 6 \\
\hline & MBTD1 & $71 \mathrm{kDa}$ & 9 & 5 & 1 \\
\hline & KAT5 & $62 \mathrm{kDa}$ & 25 & 10 & 4 \\
\hline & KAT5 & $62 \mathrm{kDa}$ & 25 & 10 & 4 \\
\hline & DMAP1 & $53 \mathrm{kDa}$ & 34 & 10 & 9 \\
\hline & RUVBL2 & $51 \mathrm{kDa}$ & 126 & 56 & 31 \\
\hline & RUVBL1 & $50 \mathrm{kDa}$ & 62 & 43 & 17 \\
\hline & ACTL6A & $47 \mathrm{kDa}$ & 35 & 21 & 15 \\
\hline & ING3 & $45 \mathrm{kDa}$ & 13 & 1 & 2 \\
\hline & АСТВ & $42 \mathrm{kDa}$ & 33 & 20 & 45 \\
\hline & VPS72 & $41 \mathrm{kDa}$ & 16 & 4 & 4 \\
\hline & MRG15 & $37 \mathrm{kDa}$ & 143 & 117 & 82 \\
\hline & YEATS4 & $27 \mathrm{kDa}$ & 12 & 4 & 3 \\
\hline & MRGBP & $22 \mathrm{kDa}$ & 20 & 13 & 7 \\
\hline & MEAF6 & $22 \mathrm{kDa}$ & 2 & 0 & 0 \\
\hline TINTIN & EP400NL & $52 \mathrm{kDa}$ & 51 & 30 & 12 \\
\hline \multirow{5}{*}{$\begin{array}{c}\text { Sin3B } \\
\text { complex }\end{array}$} & EMSY & $141 \mathrm{kDa}$ & 37 & 0 & 0 \\
\hline & PHF12/Pf1 & $110 \mathrm{kDa}$ & 13 & 0 & 0 \\
\hline & SIN3B & $133 \mathrm{kDa}$ & 5 & 0 & 0 \\
\hline & KDM5A & 192 kDa & 8 & 0 & 0 \\
\hline & RBBP4 & 48 kDa & 2 & 0 & 0 \\
\hline \multirow{4}{*}{$\begin{array}{l}\text { Other } \\
\text { factors }\end{array}$} & BRCA2 & $384 \mathrm{kDa}$ & 15 & 0 & 0 \\
\hline & ASH1L & 333 kDa & 7 & 0 & 0 \\
\hline & PALB2 & $131 \mathrm{kDa}$ & 9 & 0 & 0 \\
\hline & MRFAP1 & 15 kDa & 5 & 0 & 0 \\
\hline
\end{tabular}


Table S4. Mass spectrometry analysis of NuA4/TIP60 complex and EP400NL that interact with MRGBP and BRD8 transcripts (with 2BRDs or all transcripts (N-term CRISPR) or 1BRD), purified from K562 cells (total spectral counts). Related to Figure 4.

\begin{tabular}{|c|c|c|c|c|c|}
\hline \multirow{2}{*}{ Identified Proteins } & \multirow[b]{2}{*}{ MW } & \multicolumn{3}{|c|}{ BRD8 } & \multirow[b]{2}{*}{ MRGBP } \\
\hline & & Endogenous & $1 \mathrm{BRD}$ & 2BRD & \\
\hline TRRAP & 436 kDa & 330 & 57 & 33 & 292 \\
\hline EP400 & $340 \mathrm{kDa}$ & 275 & 74 & 42 & 296 \\
\hline RUVBL2 & $51 \mathrm{kDa}$ & 127 & 39 & 26 & 119 \\
\hline BRD8 & $135 \mathrm{kDa}$ & 117 & 68 & 23 & 114 \\
\hline RUVBL1 & 50 kDa & 84 & 26 & 18 & 93 \\
\hline EPC2 & $91 \mathrm{kDa}$ & 68 & 15 & 5 & 53 \\
\hline DMAP1 & $53 \mathrm{kDa}$ & 59 & 18 & 7 & 44 \\
\hline ACTL6A & $47 \mathrm{kDa}$ & 47 & 17 & 8 & 43 \\
\hline ATCB & $42 \mathrm{kDa}$ & 46 & 13 & 11 & 40 \\
\hline MRG15 & $40 \mathrm{kDa}$ & 44 & 35 & 7 & 200 \\
\hline MRGX & $32 \mathrm{kDa}$ & 42 & 34 & 9 & 118 \\
\hline MBTD1 & $71 \mathrm{kDa}$ & 30 & 7 & 3 & 21 \\
\hline EPC1 & $91 \mathrm{kDa}$ & 33 & 11 & 2 & 38 \\
\hline YEATS4 & $27 \mathrm{kDa}$ & 27 & 13 & 3 & 21 \\
\hline MRGBP & $22 \mathrm{kDa}$ & 23 & 17 & 5 & 89 \\
\hline ING3 & $45 \mathrm{kDa}$ & 23 & 2 & 0 & 24 \\
\hline KAT5 & $53 \mathrm{kDa}$ & 20 & 8 & 0 & 22 \\
\hline VPS72 & $42 \mathrm{kDa}$ & 14 & 6 & 3 & 18 \\
\hline MEAF6 & $22 \mathrm{kDa}$ & 8 & 3 & 0 & 8 \\
\hline $\mathrm{H} 2 \mathrm{~B}$ & $14 \mathrm{kDa}$ & & 2 & & 2 \\
\hline EP400NL & 45 kDa & 64 & 11 & 0 & 63 \\
\hline
\end{tabular}

Table S5. Mass spectrometry analysis of FPLC fraction number 23 of BRD8 and MRGBP representing TINTIN complex and number 33 of MRGBP for MRGBP/MRG15 or MRGX dimer (total spectral counts). Related to Figure 4.

\begin{tabular}{|l|l|r|r|r|}
\cline { 3 - 5 } \multicolumn{2}{c|}{} & \multicolumn{1}{c|}{ BRD8 } & \multicolumn{2}{c|}{ MRGBP } \\
\hline Identified Proteins & MW & $\begin{array}{c}\text { Fraction } \\
\mathbf{2 3}\end{array}$ & $\begin{array}{c}\text { Fraction } \\
\mathbf{2 3}\end{array}$ & $\begin{array}{c}\text { Fraction } \\
\mathbf{3 3}\end{array}$ \\
\hline BRD8 & $103 \mathrm{kDa}$ & 76 & 110 & 8 \\
\hline MRGBP & $22 \mathrm{kDa}$ & 16 & 30 & 24 \\
\hline MRG15 & $41 \mathrm{kDa}$ & 9 & 39 & 15 \\
\hline MRGX & $32 \mathrm{kDa}$ & 12 & 35 & 20 \\
\hline EP400NL & $38 \mathrm{kDa}$ & 23 & 56 & 3 \\
\hline
\end{tabular}


Table S6. Mass spectrometry analysis of EP400NL interactome purified from K562 cells through EP400NL-3xFlag 2xStrep integrated at AAVS1 or from CRISPR/Cas9-mediated tagging of the endogenous gene (total spectral counts). Related to Figure 5.

\begin{tabular}{|l|l|r|r|}
\cline { 3 - 4 } \multicolumn{1}{c|}{} & \multicolumn{2}{c|}{ EP400NL } \\
\hline BIINTIN & MW & CRISPR & Q6ZTU2-5 AAVS1 \\
\hline EP400NL & $103 \mathrm{kDa}$ & 192 & 313 \\
\hline MRG15 & $52 \mathrm{kDa}$ & 95 & 133 \\
\hline MRGX & $37 \mathrm{kDa}$ & 117 & 164 \\
\hline MRGBP & $32 \mathrm{kDa}$ & 71 & 107 \\
\hline
\end{tabular}

\begin{tabular}{|c|c|c|c|}
\hline \multirow[b]{2}{*}{$\begin{array}{l}\text { mRNA processing } \\
\text { factors }\end{array}$} & \multirow[b]{2}{*}{ MW } & \multicolumn{2}{|r|}{ EP400NL } \\
\hline & & CRISPR & Q6ZTU2-5 AAVS1 \\
\hline SRRM2 & $300 \mathrm{kDa}$ & 11 & 4 \\
\hline SF3B1 & $146 \mathrm{kDa}$ & 5 & 2 \\
\hline SF3B3 & $136 \mathrm{kDa}$ & 13 & 13 \\
\hline GEMIN4 & $119 \mathrm{kDa}$ & 2 & 0 \\
\hline U2SURP & $118 \mathrm{kDa}$ & 6 & 6 \\
\hline SF3B2 & $100 \mathrm{kDa}$ & 7 & 8 \\
\hline RBM5 & 92 kDa & 5 & 2 \\
\hline DDX20 & $92 \mathrm{kDa}$ & 2 & 1 \\
\hline HNRNPM & $78 \mathrm{kDa}$ & 14 & 15 \\
\hline PRPF31 & $55 \mathrm{kDa}$ & 12 & 6 \\
\hline HNRNPK & $51 \mathrm{kDa}$ & 7 & 4 \\
\hline HNRNPF & $46 \mathrm{kDa}$ & 3 & 5 \\
\hline RBM17 & $45 \mathrm{kDa}$ & 2 & 4 \\
\hline HNRNPC & $32 \mathrm{kDa}$ & 2 & 0 \\
\hline SNRPD3 & $14 \mathrm{kDa}$ & 2 & 1 \\
\hline
\end{tabular}




\section{Supplemental Experimental procedures}

\section{ChIP-sequencing Experiments}

For Flag ChIP, 1mg of cross-linked chromatin from K562 cells was incubated with $10 \mu \mathrm{g}$ of anti-Flag antibody (Sigma, M2) pre-bound on $300 \mu$ l of Dynabeads Prot-G (Invitrogen) overnight at $4^{\circ} \mathrm{C}$. The beads were washed extensively and eluted in $0.1 \%$ SDS, $0.1 \mathrm{M}$ NaHCO3. Crosslink was reversed with $0.2 \mathrm{M} \mathrm{NaCl}$ and incubation overnight at 65C. Samples were treated with RNase and Proteinase $\mathrm{K}$ for $2 \mathrm{~h}$ and recovered by phenol-chloroform and ethanol precipitation. Libraries for sequencing were prepared with TruSeq LT adaptors (Illumina). Samples were sequenced by 50 bp single reads on HiSeq 4000 platform (Illumina).

\section{Processing, Alignment and Peak Calling of ChIP-seq Data}

FastQ format reads were aligned to the hg19 human reference using the Bowtie alignment algorithm [63]. Bowtie2 version 2.1.6 was used with the pre-set sensitive parameter to align ChIP sequencing reads. MACS version 2.0.10 (model-based analysis of ChIPseq) peak finding algorithm was used to identify regions of ChIP-Seq enrichment over the background [64]. The pipeline, commands, and parameters that were used are: Trimming of sequence (filter out 39 adaptor, and remove last 2 bases and 3 extra bases if it matches with adaptor sequence). Mapping sequences to human genome (hg19) using Bowtie: (i) command: bowtie2 -p 8 -sensitive -x genome/genome -U sequence.reads.fastq - S sample.sam. Peak calling algorithm MACS: (i) command: macs2 callpeak -t ChIPseq.data.bam -c input.sample.file.bam --broad -f BAM -g hs -n [directory] -outdir MACS2_files --nomodel --shiftsize 100 B. Unique mapped read values were normalized to library size. Peaks were annotated as per human genome EnsDb.Hsapiens.v75 - hg19. Raw sequences and processed data of ChIP-sequencing from K562 cells were deposited in the GEO database under accession number GSE181533.

\section{Cell Cycle Analysis}

Fluorescence-activated cell sorting (FACS) analysis was used for cell cycle profiling. The cells were harvested by trypsinization, fixed with $70 \%$ ethanol, treated with propidium iodide for FACS analysis on a BD Accuri C6 Plus. 


\section{SUPPLEMENTAL FIGURE LEGENDS}

\section{Figure S1. MRG15 isoforms and MRGX chromatin binding in vitro and in vivo, related to Figs 1 and 2.}

(A) Alignment of MRG15 isoforms that have a "long" or "short" chromodomain, the paralog MRGX without chromodomain, and the Eaf3 homolog from Saccharomyces cerevisiae.

(B) Whole-cell extract of isogenic K562 cells stably expressing the indicated proteins with 3xFlag 2xStrep from the AAVS1 safe harbor locus or endogenously tagged (CRISPR MRGX).

(C) ChIP-seq analysis of MRG15-S/L and MRGX in k562 cells using the AAVS1 isogneic cell lines and antiFlag. Venn diagram of mapped significant peaks for each and overlaps. Short MRG15 isoform and MRGX bind mostly the same loci. The long MRG15 isoform shows a very small number of bound locations. Numbers represent the number of significant peaks mapped.

(D) Genomic editing with the CRISPR/Cas9 system for tagging of MRGX. Schematic of the MRGX locus, Cas9 target site, and donor construct used to insert the cassette containing 3xFlag-2xStrep in the last exon. Annotated are the positions of the stop codon the target site, the PAM motif, and homology arms left and right (HAL and R) (left). Anti-Flag analysis of MRGX whole-cell extracts from AAVS1 and taggingCRISPR K562 cell lines (right).

(E) Methyltransferase activity of ASH1L is enhanced by MRG15 in vitro, related to Fig.2.

Schematic of the ASH1L locus, Cas9 target site, and donor construct used to insert the cassette containing 3xFlag-2xStrep in the last exon. Annotated are the positions of the stop codon the target site, the PAM motif, and homology arms left and right (HAL and R).

Figure S2. CRISPR/Cas9 BRD8 and EP400NL, in K562 cells, related to Figs 4-5

(A) Whole-cell extracts (WCE) were analyzed by immunoblotting with anti-Flag. Anti-KAP1 was used as loading control. 
(B) Genomic editing with the CRISPR/Cas9 system for tagging double bromodomain (2BRD) BRD8 in Cterm and all BRD8 transcripts in N-term. Schematic of the BRD8 locus, Cas9 target site, and donor construct used to insert the cassette containing 3xFlag-2xStrep in the last exon for 2BRD or first exon for all transcripts. Annotated are the positions of the stop codon the target site, the PAM motif, and homology arms left and right (HAL and R).

(C) Anti-Flag analysis of BRD8 whole-cell extracts from AAVS1 and tagging-CRISPR K562 cell lines.

(D) Alignment to see the similarity of human N-term EP400 and new subunit human EP400NL.

(E) Genomic editing with the CRISPR/Cas9 system for tagging EP400NL in C-term. Schematic of the EP400NL locus, Cas9 target site, and donor construct used to insert the cassette containing 3xFlag2xStrep in the last exon. Annotated are the positions of the stop codon the target site, the PAM motif, and homology arms left and right (HAL and R).

(F) EP400NL expression from CRISPR or AAVS1 K562 cells. Anti-GAPDH is used as loading control.

Figure S3. KDs TIP60 versus TINTIN subunits in U2OS, related to Fig 6.

(A) Validation of the different siRNAs used for RNA sequencing analyses by RT-qPCR. RPLPO was used as control. Different sets of primers were annotated. Knowdowns were normalized with the siControl (siLuciferase) (mean \pm s.e.m, $n=2$ ).

(B) Cell cycle profile analysis of U2OS cells $48 \mathrm{hrs}$ after transfection of the different siRNAs. Error bars represented range of two independent experiments.

Statistical analyses were performed by two-way ANOVA test followed by Tukey's test, ${ }^{*}, \mathrm{p}<0.1,{ }^{* *}, \mathrm{p}<$ $0.01, * * * *, \mathrm{p}<0.0001$

(C) 253 genes are downregulated (left) and 142 genes are upregulated (right) by KDs of TINTIN subunits (BRD8, MRGBP, and MRGX) but not NuA4/TIP60 complex. To highlight the genes with high changes in 
bioRxiv preprint doi: https://doi.org/10.1101/2021.08.11.456009; this version posted August 12, 2021. The copyright holder for this preprint (which was not certified by peer review) is the author/funder, who has granted bioRxiv a license to display the preprint in perpetuity. It is made available under aCC-BY-NC-ND 4.0 International license.

expression, a cutoff of 2 -fold difference was applied to the Log2(fold change) values between the selected KDs and control (siLuc).

(D) Gene ontology analysis for downregulated (left) and upregulated genes (right) showing a significant enrichment (pValue <0.01) using DAVID 6.8. 
bioRxiv preprint doi: https://doi.org/10.1101/2021.08.11.456009; this version posted August 12, 2021. The copyright holder for this preprint

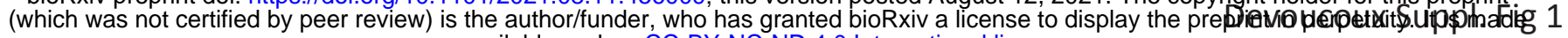
available under aCC-BY-NC-ND 4.0 International license.

A

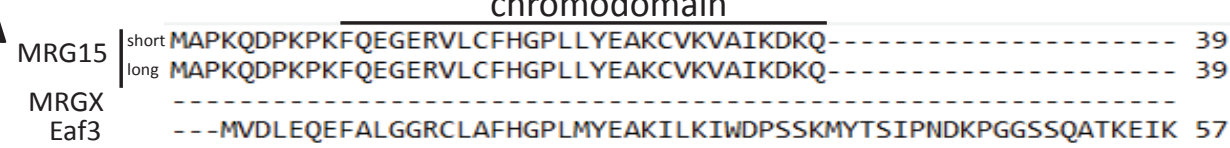

chromodomain

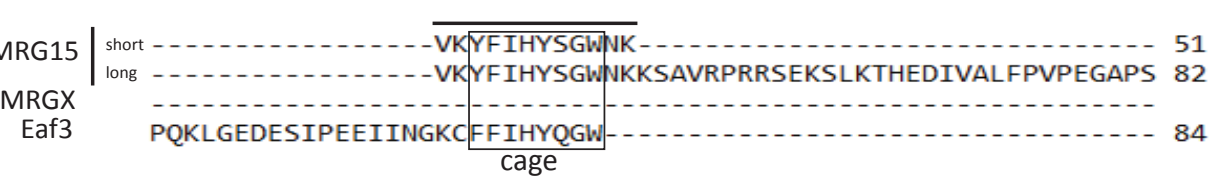

MRG15 short - - - - - NWDEWVPESRVLKYVDTNLQKQRELQKANQEQ- - - - - YAE- - - GKMRGA 92| MRGX Iong VHHPLLTSSWDEWVPESRVLKYVDTNLQKQRELQKANQEQ--.-.-YAE-.--GKMRGA 131

Eaf3 -...-MSSRKQGSQPR -.....-GQQSAEEENFKKPTRSN -.....-MQR -..-SKMRGA 37 - - - -KSSWDEWNGYDRIRAYNEENIAMKKRLANEAKEAKKSLLEQQKKKKLSTSLGGP 138

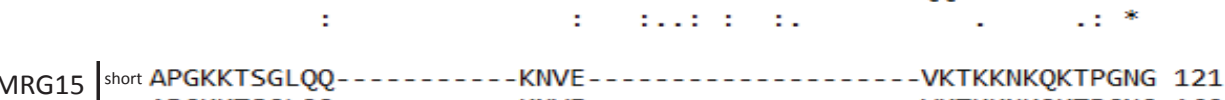
MRG15 $\begin{aligned} & \text { short APGKKTSGLQQ- } \\ & \text { Iong APGKKTSGLQQ- }\end{aligned}$ MRGX SSGKKTAGPQQ--...-.-KNLEPALPGRWGGRSAENPPSGSVRKTRKNKQKTPGNG 86 Eaf3 SNGGKRKGDSRSNASISKSTSQSFLTSSVSGRKSGRSSANS -............ LHPGSS 185 : *** .: . :

MRG15 short DGGSTSETPQPPRKKRARVDPTVENEETFMNRVEVKVKIPEELKPWLVDDWDLITRQKQL 181 Iong DGGSTSETPQPPRKKRARVDPTVENEETFMNRVEVKVKIPEELKPWLVDDWDLITRQKQL 220 MRGX DGGSTSEAPQPPRKKRARADPTVESEEAFKNRMEVKVKIPEELKPWLVEDWDLVTRQKQL 146 Eaf3 LRSSSDQNGNDDRRRSSSLSPNMLHHIAGYPTPKISLQIPIKLKSVLVDDWEYVTKDKKI 245

$$
\text { .*:.: : *: : : .*.: . : : : : : :**:** **:**: :*::*:: }
$$

MRG15 short FYLPAKKNVDSILEDYANYKKSRGNTDNKEYAVNEWVAGIKEYFNVMLGTQLLYKFERPQ 241 long FYLPAKKNVDSILEDYANYKKSRGNTDNKEYAVNEWNGIKEYFNVMLGTQLLYKFERPQ 280 MRGX FQLPAKKNVDAILEEYANCKKSQGNVDNKEYAVNEVVAGIKEYFNVMLGTQLLYKFERPQ 206 Eaf3 CRLPADVTVEMVLNKYEHEVSQELESPGSQSQLSEYCAGLKLYFDKCLGNMLLYRLERLQ 305 ***. .*: :*:.*: . . : . : : :* **:***: **. ***::***

MRG15 short YAEILADHPDA-PMSQVYGAPHLLRLFVRIGAMLAYTPLDEKSLALLLNYLHDFLKY 297 Iong YAEILADHPDA- - - PMSQVYGAPHLLRLFVRIGAMLAYTPLDEKSLALLLNYLHDFLKY 336 MRGX YAEILLAHPDA--.-PMSQVYGAPHLLRLFVRIGAMLAYTPLDEKSLALLLGYLHDFLKY 262

Eaf3 YDELLKKSSKDQKPLVPIRIYGAIHLLRLISVLPELISSTTMDLQSCQLLIKQTEDFLVW 365 **:* . : :********: : :::*:*:**: .***:

MRG15 shortLAKNSATLFSASDYEV - - - - - APPEYHRKAV- - 323

MRG15 Iong LAKNSATLFSASDYEV - . . . - APPEYHRKAV - 362

MRGX LAKNSASLFTASDYKV -...-.-ASAEYHRKAL -- 288

Eaf3 LLMHVDEYFNDKDPNRSDDALYVNTSSQYEGVALGM 401

* : *..*: : :*. *:
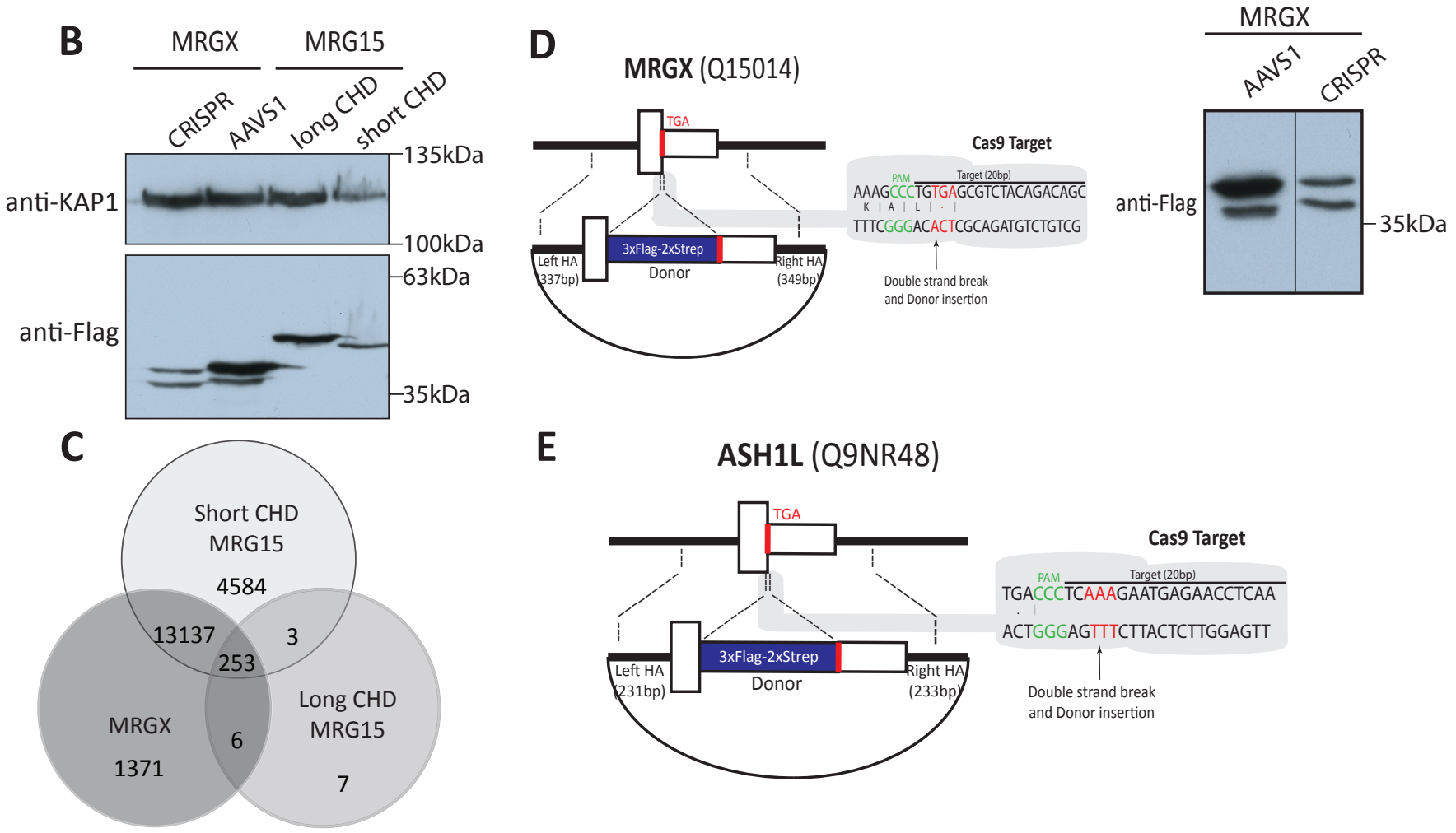

E

ASH1L (Q9NR48)

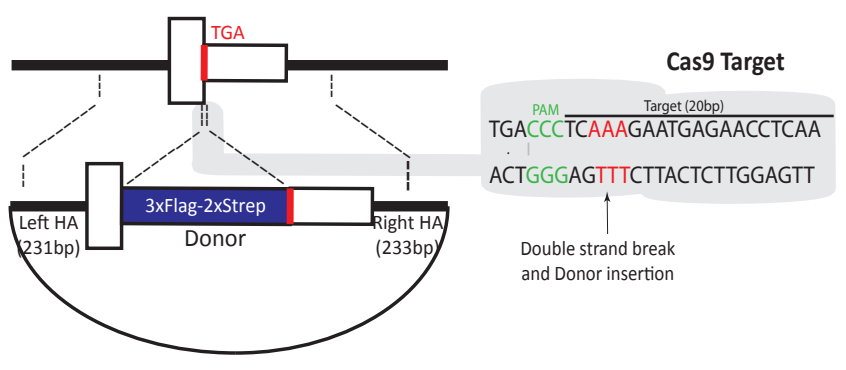


bioRxiv preprint doi: https://doi.org/10.1101/2021.08.11.456009; this version posted August 12, 2021. The copyright holder for this preprint (which was not certified by peer review) is the author/funder, who has granted bioRxiv a license to display the preprint in perpetuity. It is made available under aCC-BY-NC-ND 4.0 International license.

Devoucoux Suppl. Fig 2

A

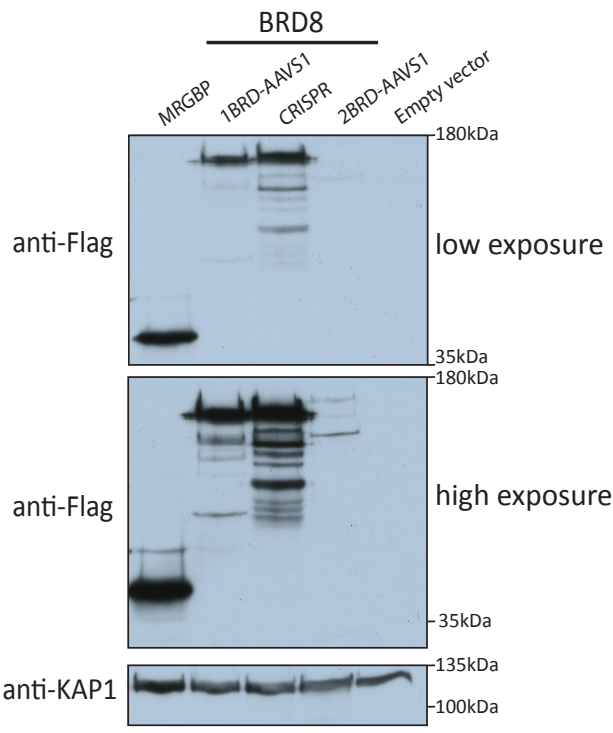

B

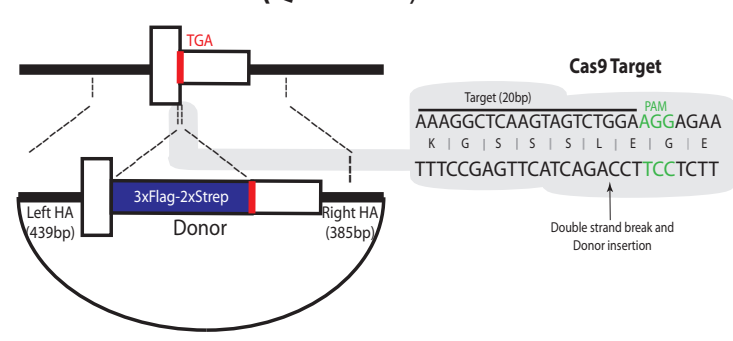

BRD8 (all transcripts)

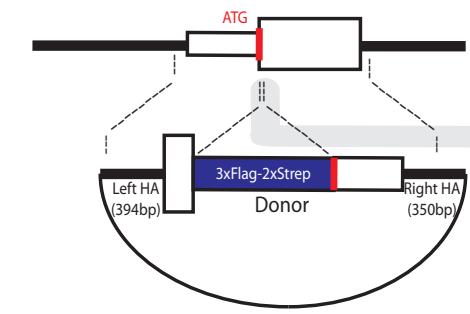

C

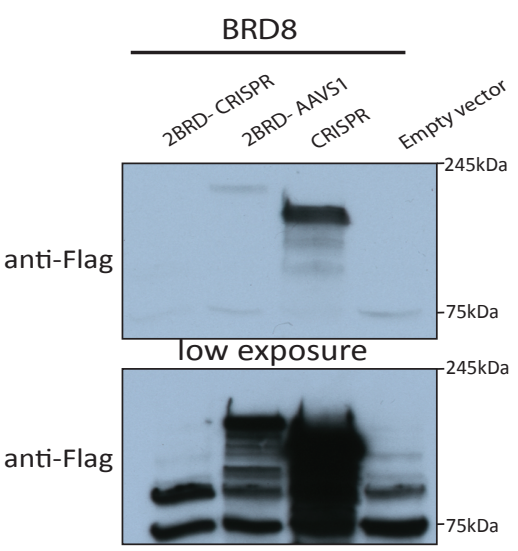

high exposure

$75 \mathrm{kDa}$
D

EP400 MHHGTGPONVOHQLQRSRACPGSEGEEQPAHPNPPPSPAPFAPSASPSAPQSPSYQIQQ 60 EP40ONL-5 MQHVSSSQSSQRHVQWPGACPGAGE-EQPACSQPS-......-LPLTLPSPSHQLQQ 48

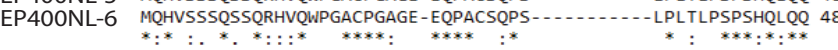

EP400 LM-NRSPATGQNVNITLQSVGPVVGGNQQITLAPLPLPSPTSPGFQFSAQPRRFEHGSPS 119

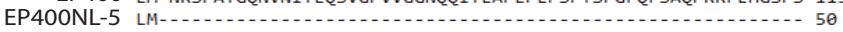
EP400NL-6 LMVRGGPAGGQNMNVDLQGVGPGLQGSPQVTLAPLPLPSPTSPGFQFSAQPRRFEHGSPS 108

EP400 YIQVTSPLSQQVQTQSPTQPSPGPGQALQNVRAGAPGPGLGLCSSSPTGGFVDASVLVRQ 179 EP400NL-5 168

EP400 ISLSPSSGGHFVFQDGSGLTQIAQGAQVQLQHPGTPITVRERRPSQPHTQSGGTIHHLGP 239 - - DGSGLTOIAQGAOVOLOHPGTPITVRERRPSOPHTOSGGTIHHLGP 96 EP400NL-6 ISLSPSSGGHFVFDGSGLTQIAQGAQVQLQHPGTPITVRERRPSQPHTQSGGTIHHLGP 228

EP400 QSPAAAGGAGLQPLASPSHITANLPPQISSIIQGQLVQQQQVLQGPPLPRPLGFERTPG 299 EP400NL-5 QSPAAAGGAGLOPLASPSHITTANLPPOISSIIOGQLVOOOOVLOGPPLPRPLGFERTPG 156 EP400NL-6 QSPAAAGGAGLQPLASPSHITTANLPPQISSIIQGQLVQQQVLQGPPLPRPLGFERTPG 288

EP400 VLLPGAGGAAGFGMTSPPPPTSPSRTAVPPGLSSLPLTSVGNTGMKKVPKKLEEIPPASP 359 EP400NL-5 VLLPGAGGAAGFMTSPPPPTSPSRTAVPPGLSSLPLTSVGNTGMKKVPKKLEETPPASP 216 EP400NL-6 VLLPGAGGAAGFMTSPPPPTSPSRTAVPPGLSSLPLTSVGNTGMKKVKKLEEIPPA VLLPGAGGAAGFGMTSPPPPTSPSRTAVPPGLSSLPLTSVGNTGMKKVPKKLEEIPPASP 348

EP400 EMAOMRKOCLDYHYOEMOALKEVFKEYLIELFFLOHFOGNMMDFLAFKKKHYAPLOAYLR 419 EP4OONL-5 EMAOMRKOCLDYHHOEMOALKEVFKEYLIELFFLOHFOGNMMDFLAFKERLYGPLOAYLR 276 EP400NL-6 EMAOMRKOCLDYHHOEMOALKEVFKEYLIELFFLOHFOGNMMDFLAFKERLYGPLOAYLR 408 EMAQMRKQCLDYHHQEMQALKEVFKEYLIELFFLQHFQGNMMDFLAFKERLYGPLQAYLR 408

EP400 ONDLDIEEEEEEEEEEEKSEVINDEVKVVTGKDGOTGTPVAIATOLPPKVSAAFSSOOQ 479 EP400NL-5 QNDLDIEEEE--.--EEHFEVINDEVKVVARKHGQPGTPVAIATQLPPRTSAAFPAQQQ 330 EP400NL-6 QNDLDIEEEE-...--EEHFEVINDEVKVVARKHGQPGTPVAIATQLPPRTSAAFPAQQQ 462

EP400 PFOOALAGSLVAGAGSTVETDLFKROOAMPSTGMAEOSKRPRLEVGHOGVVFOHPGADAG 539 EP40ONL-5 PLQVLSDGSTVQLPRL-_-_._- 356 EP400NL-6 PLQVLSDGSTVQLPRL-....... SSLGFEDSMC - $\ldots$

EP400 VPLQQLMPTAQGGMPPTPQAAQLAGQRQSQQQYDPSTGPPVONAASLHTPLPQLPGRLPP 599 EP400NL-5 EP400NL-6

$\mathbf{E}$
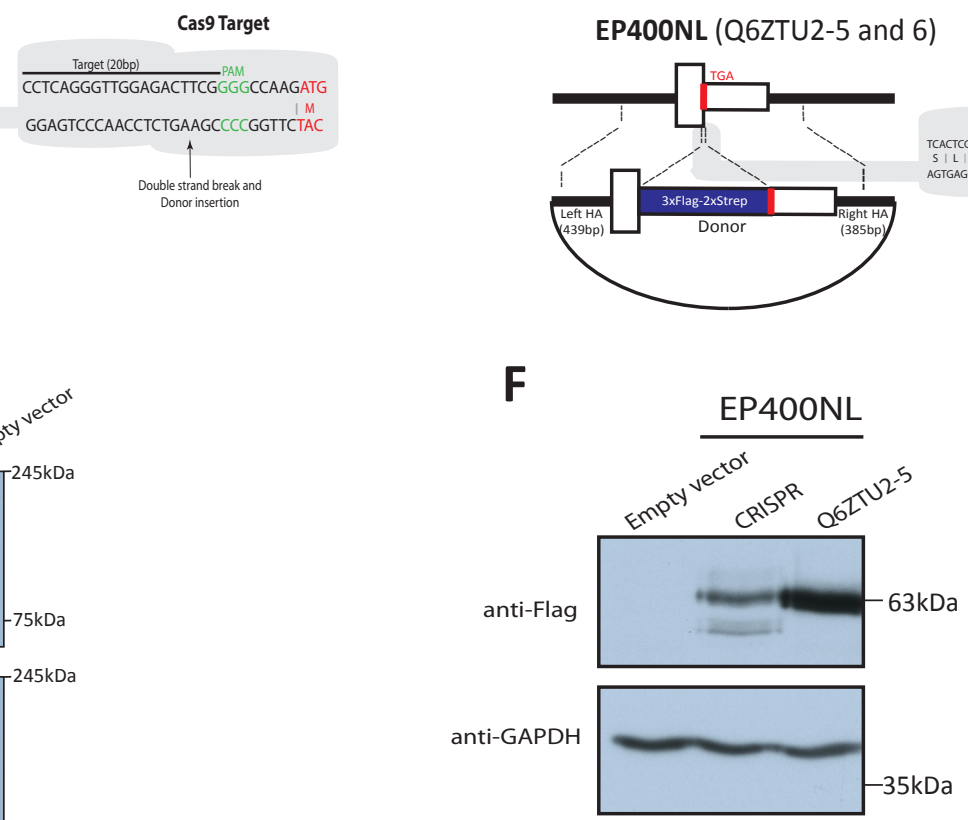
